\title{
Converting Homogeneous to Heterogeneous in Electrophilic Catalysis Using Monodisperse Metal Nanoparticles
}

\author{
Cole A. Witham, Wenyu Huang, Chia-Kuang Tsung, John N. Kuhn, Gabor A. Somorjai, ${ }^{\star}$ F. Dean Toste* \\ Department of Chemistry, University of California, Berkeley, California 94720, and Chemical and Materials Sciences \\ Divisions, Lawrence Berkeley National Laboratory, 1 Cyclotron Road, Berkeley, California 94720 \\ *E-mail: somoriai@berkeley.edu; fdtoste@berkeley.edu
}

A continuing goal in catalysis is the transformation of processes from homogeneous to heterogeneous. To this end, nanoparticles represent a new frontier in heterogeneous catalysis, where this conversion is supplemented by the ability to obtain new or divergent reactivity and selectivity. We report a novel method for applying heterogeneous catalysts to known homogeneous catalytic reactions through the design and synthesis of electrophilic platinum nanoparticles. These nanoparticles are selectively oxidized by the hypervalent iodine species $\mathrm{PhICl}_{2}$, and catalyze a range of $\pi$-bond activation reactions previously only homogeneously catalyzed. Multiple experimental methods are utilized to unambiguously verify the heterogeneity of the catalytic process. The discovery of treatments for nanoparticles that induce the desired homogeneous catalytic activity should lead to the further development of reactions previously inaccessible in heterogeneous catalysis. Furthermore, our size and capping agent study revealed that Pt PAMAM dendrimer-capped nanoparticles demonstrate superior activity and recyclability compared to larger, polymer-capped analogues.

The field of homogeneous catalysis can be characterized as a source of easily tuned, selective catalysts with high activity. Heterogeneous catalysts also offer many advantages, some of which are not displayed by their homogeneous counterparts, including recyclability, ease of separation from the reaction mixture and use in continuous flow processes. It is highly desirable to develop new systems that blend the many advantages of heterogeneous catalysis with the versatility of homogeneous catalysts. ${ }^{1-3}$ Most efforts approach from the homogeneous side and are comprised of immobilized homogeneous catalyst species that promote reactions already accessible by homogeneous solution-state conditions. ${ }^{1,4}$ We sought to utilize an alternative method wherein heterogeneous catalysts are extended to reactions previously only catalyzed by homogeneous species. Metal nanoparticles (NPs) that serve as heterogeneous catalysts in which the metal particle size and oxidation state can be characterized are well-suited for our study. In addition, it is known that the reactivity and selectivity of monodisperse metal NPs can be altered by changes in their size and shape. ${ }^{5-15}$ Although Pd and Au NPs have been demonstrated to catalyze a range of cross-coupling and oxidation/reduction reactions in solution, ${ }^{16-25}$ studies have not yet yielded the control necessary to develop new NP catalysts applicable to a wider variety of reactions.

A further challenge involves the specific nature of the catalyst. In particular, the distinction between homogeneous and heterogeneous catalysis is often difficult to determine. This is due to the possibility that metal leaches from a heterogeneous catalyst into solution and acts as the catalytically active species. Thus, it was important for us to consider in our studies the fact that for many of the NPs used in carboncarbon bond forming reactions, formation of a catalytically active homogeneous species from the NP precursor cannot be excluded. For example, it is generally accepted that Pd nanoparticles, when used in solution, degrade into various homogeneous species and provide a strong case for the assumption that a nanoparticle catalyst is leaching in solution until proven heterogeneous. ${ }^{2,16,17,25}$ Thus, we aimed to design and synthesize truly heterogeneous NPs capable of catalyzing an alternative yet broad class of reactions for functionalizing $\pi$-bonds that, to date, has been achieved exclusively with homogeneous catalysts. To accomplish this goal, the NP catalysts would require significant electrophilic character likely imparted by an increase in metal oxidation state, similar to that found in electron-deficient, latemetal homogeneous catalysts. In doing so, we would obtain new activity from heterogeneous metal NP catalysts resulting in selective, solution-phase carbon-carbon and carbon-heteroatom bond forming reactivity not previously observed with known heterogeneous catalysts. 


\section{Results and Discussion}

\section{Catalyst Development and Reactivity}

Given that the aforementioned set of desired transformations are currently known to be catalyzed by Pt halides, we focused our study on Pt NPs. Two general types of NPs were prepared in a range of sizes that allow for thorough investigation of the effects of various parameters on reactivity. These Pt NPs were synthesized utilizing two techniques: dendrimer or polymer encapsulation (Figure 1a). Fourth generation hydroxyl terminated polyamidoamine (PAMAM) dendrimers (G4OH) were used as a capping agent ${ }^{4,17,26}$ for smaller sized 1.0 $\mathrm{nm} 40$ atom $\mathrm{Pt}\left(\mathrm{Pt}_{40}\right)$ NPs. Alternatively, polyvinylpyrrolidone (PVP) was used to generate 1.5, 2.9 and $5.0 \mathrm{~nm}$ sized NPs by existing procedures. ${ }^{27}$ Fabrication of the NPs was followed by deposition onto SBA-15 or, in the case of the larger 5.0 nm NPs, MCF-17 mesoporous silica. Notably, NPs capped with PAMAM dendrimers are active for a variety of reactions when supported on SBA-15 silica and calcinations or other similar manipulations of the NPs are not necessary, unlike PVP or other capping agents. ${ }^{26,28}$ In addition to allowing for recycling of the catalyst, deposition of the PAMAM dendrimer NPs on SBA-15 imparts additional thermal stability against aggregation. ${ }^{4,26,28}$ Furthermore, since PAMAM dendrimers are normally soluble only in protic liquids, loading the NPs on SBA-15 allows for their use in organic solvents.

Our initial studies focused on a hydroalkoxylation reaction in which an electrophilic Pt catalyst activates an alkyne towards nucleophilic attack by an oxygen functionality. ${ }^{29}$ When $1.5 \mathrm{~nm}$ Pt/PVP/SBA-15 NPs were used, no appreciable reaction was observed. Given that the homogeneous Pt catalysts for this type of reaction exist in the $(+2)$ or $(+4)$ oxidation state, we hypothesized that the failure of the NPs was due to an overabundance of Pt in the (0) oxidation state. In fact, X-ray photoelectron spectroscopy (XPS) studies on these Pt/PVP NPs have confirmed that $>90 \%$ of the metal exists in a metallic $\mathrm{Pt}(0)$ oxidation state. Thus, we turned to the $\mathrm{Pt}_{40} / \mathrm{G} 4 \mathrm{OH} \mathrm{NPs}$, which are $>70 \%$ oxidized as determined by XPS. ${ }^{30-32}$ However, exposure of alkyne 1 to $1.0 \mathrm{~nm} \mathrm{Pt}_{40} / \mathrm{G} 4 \mathrm{OH}$ NPs generated only a $10 \%$ yield of product. This result is likely due to the presence of catalytically inactive Pt oxide species on the $\mathrm{Pt}_{40} / \mathrm{G} 4 \mathrm{OH}$ NP surface. To address this lack of activity, we postulated that known oxidizing agents for metals might be used to selectively modify the NP surface to produce a catalyst species with the requisite activity. Recent work has shown the formation of oxidized $\left[\mathrm{PtCl}_{4}\right]^{2-}$ layers on $\mathrm{Pt}$ surfaces with $\mathrm{Cl}_{2}$ etching, ${ }^{33}$ as well as oxidation of $\mathrm{Pd}$ catalysts to form $\mathrm{Pd}-\mathrm{Cl}$ bonds with the hypervalent iodine species iodosobenzene dichloride $\left(\mathrm{PhICl}_{2}\right){ }^{34} \mathrm{These}$ precedents serve to reinforce the ability of $\mathrm{PhICl}_{2}$ to act as a mild oxidant to transform the Pt NP surface into a catalytically active state. Gratifyingly, we found that $\mathrm{PhICl}_{2}$ successfully generated the desired electrophilic catalyst species. Treatment of either $\mathrm{Pt}$ 15 (further reduced under $\mathrm{H}_{2}$ atmosphere at $100^{\circ} \mathrm{C}$ for $24 \mathrm{~h}$ prior to reaction) or Pt/PVP/SBA-15 NPs with three equivalents (relative to catalyst loading) of $\mathrm{PhICl}_{2}$ resulted in an excellent yield of $>95 \%$ for benzofuran 2 (Figure $1 \mathrm{~b}$ ). Further evidence for the oxidation of the $\mathrm{Pt}$ NPs was obtained from an XPS spectrum of $1.5 \mathrm{~nm} \mathrm{Pt} / \mathrm{PVP}$ NPs treated with $\mathrm{PhICl}_{2}$ showing that $>25 \%$ of the Pt was oxidized.

\footnotetext{
Figure 1. Depiction of the nanoparticle synthesis for the two capping agents, and the initial reactivity results for electrophilic catalysis. a) In the top scheme, Pt ions are loaded onto a PAMAM dendrimer and reduced to form a dendrimer encapsulated NP. Sonication deposits the NPs on the mesoporous silica SBA-15 to generate the NP catalysts. In the bottom scheme, polyvinylpyrrolidone encapsulates the NP. Deposition on SBA-15 follows to produce the catalyst. In both cases, the NPs are synthesized before loading onto SBA-15. b) Hydroalkoxylation of 1 with Pt NPs. To obtain electrophilic activity from the Pt NPs, treatment with the mild oxidant $\mathrm{PhICl}_{2}$ is required. $\mathrm{Pt}_{40} / \mathrm{G} 4 \mathrm{OH} / \mathrm{SBA}-15 \mathrm{NPs}$ must be further reduced under $\mathrm{H}_{2}$ atmosphere at $100^{\circ} \mathrm{C}$ for $24 \mathrm{~h}$ prior to reaction. This treatment generates catalytically active NPs which activate the $\pi$-bond in $\mathbf{1}$ resulting in hydroalkoxylation to benzofuran 2. Yields determined by NMR vs internal standard.
}

As predicted, the oxidized NP catalysts demonstrated a size and capping agent effect on catalytic activity. Although multiple studies conducted on various reactions in both the gas and solution phase have demonstrated the importance of NP parameters for reactivity and selectivity, fewer discuss supported NPs in solution. ${ }^{5-15,35}$ Under our oxidative modification conditions, additional size and capping agent effects were found for the PVP and dendrimer capped, SBA-15 supported Pt NPs. Results from detailed reaction monitoring indicate that smaller, dendrimer capped NPs are more stable in higher oxidation states than larger NPs and remain in this catalytically active state for prolonged times. Based on previous observations, this trend may be due to the stability imparted by the PAMAM dendrimer NPs with higher oxidation states. ${ }^{26,28,30-32}$ It is also possible that, under the reaction conditions, the dendrimer could decompose. However, any decomposition does not appear to affect the catalytic activity as evidenced by the similar activity of the $\mathrm{Pt} 40 / \mathrm{G} 4 \mathrm{OH} / \mathrm{SBA}-15 \mathrm{NP}$ catalyst after recycling and its consistent difference from the PVP capped NPs. Furthermore, recent reports that suggest more harsh conditions are 
required for complete dendrimer removal. ${ }^{31,36,37}$ Regardless, $\mathrm{Pt}_{40}$ proved to be the most robust catalyst and, after oxidative modification with $\mathrm{PhICl}_{2}$, maintained a steady rate of reaction, only to decrease as the reaction neared complete consumption of starting material (Figure 2a). The stability of the $\mathrm{Pt}_{40}$ catalyst was additionally tested by isolation of the SBA-15 supported catalyst and immediate resubmission to a new solution of substrate. In this case, an overall decrease in activity was observed, but the catalyst remained consistently active until all substrate was consumed with no further deactivation. The $\mathrm{Pt}_{40} / \mathrm{G} 4 \mathrm{OH}$ PAMAM NPs, when supported on SBA-15, showed excellent recyclability over multiple cycles after simple filtration, reduction and retreatment with $\mathrm{PhICl}_{2}$ (Figure $2 \mathrm{~b}$ ). A sample of Pt 40 G4OH/SBA15 NPs has been recycled four times with a consistent yield of $>90 \%$ under the reported reaction conditions. In addition, a single batch of catalyst was active for a month, and a turnover number of 400 (per metal basis) was obtained. Monitoring of the reaction indicated no loss of activity after recycling as compared to the initial catalyst use, and simple filtration of the catalyst through a glass microfiber filter was sufficient to separate the metal species from the product solution. Much like their use in the gas-phase, PAMAM dendrimers exhibit significant advantages as NP capping agents in solution. This templating strategy allows for the generation of monodisperse NPs as small as $1 \mathrm{~nm}$ and is complemented by the resulting performance enhancements and potential for further catalyst development in combination with the oxidative modification.

Figure 2. Monitoring the reaction using Pt NP catalysts to show size and capping agent effects as well as recyclability. Graphs display the reaction yield of $\mathbf{2}$ from $\mathbf{1}$ as a function of time. All catalysts treated with $\mathrm{PhICl}_{2}$ (3 catalytic equiv.) For $\mathrm{Pt}_{40} / \mathrm{G} 4 \mathrm{OH} / \mathrm{SBA}-15$ (3 mol\%) (a) initial run, and (b) recycled. For $1.5 \mathrm{~nm}$ Pt/PVP/SBA-15 (1 mol\%) (c) initial run, and (d) recycled ( $80 \mathrm{~h}$ reaction time). Note the excellent recyclability of the $\mathrm{Pt}_{40} / \mathrm{G} 4 \mathrm{OH}$ catalyst as opposed to the significant deactivation of the Pt/PVP NPs.

For larger NP sizes, PVP capping was required. However, the 1.5, 2.9 and $5.0 \mathrm{~nm} \mathrm{Pt} / \mathrm{PVP} / \mathrm{SBA}-15 \mathrm{NPs}$ had distinctly different activity from the smaller, dendrimer capped NPs. In addition to a decrease in activity as NP size increased, these larger NPs demonstrated a marked initial spike in activity, followed by rapid deactivation and prolonged time to reach completion (Figure 2c). For example, when only $1 \mathrm{~mol} \%$ of $1.5 \mathrm{~nm} \mathrm{Pt/PVP/SBA}-15 \mathrm{NPs}$ treated with $\mathrm{PhICl}_{2}$ were used, approximately $70 \%$ yield was reached in the first 1.5 hours. Then, nearly 60 hours were required to reach complete conversion to product. Immediate resubmission of the PVP NPs to a new batch of substrate did indeed prove the catalyst was deactivated, as the reaction was extremely slow and never reached completion in significantly more time than initially required. Even after reduction and $\mathrm{PhICl}_{2}$ retreatment of the recycled catalyst, substantial deactivation of the catalyst was observed (Figure 2d). In comparison, $2 \mathrm{~mol} \%$ of $\mathrm{PhICl}_{2}$ oxidized $5.0 \mathrm{~nm} \mathrm{Pt} / \mathrm{PVP} / \mathrm{SBA}-15 \mathrm{NPs}$ generated only $14 \%$ yield in the initial activity spike, and after 70 hours, only $60 \%$ yield was obtained, demonstrating the decrease in activity resulting from larger NP sizes. It is important to note that while the PVP capped catalyst did exhibit a more rapid deactivation, a batch of $2.9 \mathrm{~nm}$ Pt/PVP/SBA-15 NPs treated with $\mathrm{PhICl}_{2}$ remained active for one month. A turnover number of 415 (per metal basis) was obtained. For these larger NP sizes, we believe that the NP has more metallic character and tends to revert to the $\operatorname{Pt}(0)$ oxidation state. ${ }^{38-40}$ With smaller sizes, the NP more readily retains its oxidized state as the electronic valency of the surface atoms is less saturated and more atomic character is present. It is also likely that the increased activity of smaller NPs is due to the larger number of Pt atoms, and therefore active sites after treatment with $\mathrm{PhICl}_{2}$, present on the surface of the NP. Beyond size considerations, the increased rate of deactivation and limited recyclability for the PVP capping agent renders the oxidatively modified PAMAM dendrimer capped NPs as the optimal catalyst system.

Having developed two highly active Pt NP catalysts, we sought to test them for a range of $\pi$-bond activation reactions previously known to occur only with electrophilic homogeneous catalysts. Gratifyingly, the NPs were found to catalyze several reactions in the solutionphase under relatively mild conditions with minimal or no side-reactions. Figure 3 shows the results of these reactions with both G4OH PAMAM dendrimer and PVP capping agents. Five- and six- membered ring heterocycles were formed by addition of nitrogen and oxygen nucleophiles to alkynes and allenes (Figure 3a-c), ${ }^{41,42}$ activated by the Pt nanoparticle catalysts. Carbon-carbon bond formation has also been accomplished utilizing a hydroarylation reaction (Figure $3 \mathrm{~d}$ ). ${ }^{43}$ It is important to note that all reactions are catalyzed by Pt NPs in yields comparable to, if not slightly better than those obtained with homogeneous $\mathrm{PtCl}_{2}$. Furthermore, in the case of the cyclization of compound 9, our NP catalysts show selectivity favoring the para-isomer $\mathbf{1 0}$ over the ortho-isomer, nearly equivalent to that observed in homogeneous $\mathrm{PtCl}_{2}$ systems. This highlights the potential of unique heterogeneous catalysts to offer similar selectivities relative to homogeneous species. Generality for the oxidative treatment was shown when $\mathrm{Pd}_{40} / \mathrm{G} 4 \mathrm{OH} / \mathrm{SBA}-15 \mathrm{NPs}$ were used for the formation of 2 from 1 (Figure 4). Just as was found for Pt, the Pd NPs required further reduction $\left[\mathrm{H}_{2}(1 \mathrm{~atm}), 100^{\circ} \mathrm{C}, 24 \mathrm{~h}\right]$ followed by in situ treatment 
with $\mathrm{PhICl}_{2}$ to generate electrophilic catalytic activity. The yield obtained with the Pd NPs (48\%) was comparable to that obtained with $\mathrm{PdCl}_{2}$ homogeneous catalyst.

Figure 3. Cyclization Reactions of Pt NPs. Both PVP and dendrimer encapsulated NPs result in good to excellent yields of nitrogen and oxygen containing heterocycles resulting from $\pi$-bond activation by electrophilic Pt. Catalyst systems: A: $\mathrm{Pt}_{40} / \mathrm{G} 4 \mathrm{OH} / \mathrm{SBA}-15$ (4 mol\%), $\mathrm{PhICl}_{2}\left(12 \mathrm{~mol} \%\right.$ ); B: $2.9 \mathrm{~nm} \mathrm{Pt} / \mathrm{PVP} / \mathrm{SBA}-15$ (2.5 mol\%), $\mathrm{PhICl}_{2}\left(7.5 \mathrm{~mol} \%\right.$ ); $\mathrm{C}_{\mathrm{PtCl}}(5 \mathrm{~mol} \%) . \mathrm{Pt}_{40} / \mathrm{G} 4 \mathrm{OH} / \mathrm{SBA}-15$ NPs must be further reduced under $\mathrm{H}_{2}$ atmosphere at $100^{\circ} \mathrm{C}$ for $24 \mathrm{~h}$ prior to reaction. Yields determined by NMR vs internal standard. Figure $3 \mathrm{~d}$, catalyst system $\mathrm{C}$ reacted at $80^{\circ} \mathrm{C}$ for $17 \mathrm{~h} .{ }^{43}$

Figure 4. Cyclization Reaction with Pd NPs. Reaction with Pd NPs demonstrates generality for the oxidative modification. $\mathrm{Pd}_{40} / \mathrm{G} 4 \mathrm{OH} / \mathrm{SBA}-15 \mathrm{NPs}$ must be further reduced under $\mathrm{H}_{2}$ atmosphere at $100^{\circ} \mathrm{C}$ for $24 \mathrm{~h}$ prior to reaction. Yields determined by NMR vs internal standard.

\section{Leaching Tests}

While the remarkably consistent recyclability of the $\mathrm{PhICl}_{2}$ treated $\mathrm{Pt}_{40} / \mathrm{G} 4 \mathrm{OH} / \mathrm{SBA}-15 \mathrm{NPs}$ is a strong indication of its heterogeneity, we wanted further verification that the NPs were not leaching to form a homogeneous active catalyst. To demonstrate that the NP activity was not attributable to leaching of $\mathrm{PtCl}_{2}$ or $\mathrm{PtCl}_{4}$ species, we examined a reaction that is not catalyzed by either of these two compounds. We turned to a recent report of a dehydroalkoxylation-cyclization cascade reaction in which $\mathrm{PtI}_{4}$ was the only catalyst to demonstrate appreciable activity for the formation of tetracycle $13 .{ }^{44}$ We confirmed that when urea 11 was treated with either $\mathrm{PtCl}_{2}$ or $\mathrm{PtCl}_{4}$ homogeneous catalyst in toluene at $110^{\circ} \mathrm{C}$, only a low yield of $\mathbf{1 3}$ was observed. Addition of three catalytic equivalents of $\mathrm{PhICl}_{2}$ to the homogeneous salt also did not result in any change in reaction conversion or yield. However, both Pt/PVP/SBA-15 and Pt $40 / \mathrm{G} 4 \mathrm{OH} / \mathrm{SBA}-$ 15 NPs oxidatively modified with $\mathrm{PhICl}_{2}$ resulted in $43-48 \%$ yield after $48 \mathrm{~h}$ for a completely different product, the bis-indole 12 (Figure

5). While small amounts of the tetracycle 13 were formed by the NP catalysts, the majority of the consumed starting material went towards this alternative catalytic reaction pathway. This remarkable outcome not only represents divergent reactivity from homogeneous catalysts, but is further evidence that the unique properties of NPs can result in new transformations and catalyst selectivity beyond what homogeneous catalysts can provide. ${ }^{45,46}$ In this case, not only does a different nitrogen act as the nucleophile, but the NPs catalyze a cascade that results in the formation of several new carbon-carbon bonds to afford 12, a transformation unprecedented in homogeneous catalysis. This reaction also provides support for the assertion that no leaching of the NP catalysts occurs to form homogeneous catalytically active species, in that no appreciable amount of bis-indole $\mathbf{1 2}$ was obtained from Pt salts that could potentially form in situ. Moreover, the NPs generate alternative products than expected with homogeneous catalysts and can be considered a unique metal species distinct even from the concept of supported homogeneous catalysts which would form $\mathbf{1 3}$ in analogy to unanchored homogeneous catalysts.

Figure 5. Oxidatively modified Pt NP catalyzed cyclization of phenylurea 11. While homogeneous catalysts provided low yields of tetracycle 13, the NPs result in an unprecedented reaction to the methylene-bridged bis-indole compound 12.

The striking improvement in long-term activity of the smaller sized PAMAM dendrimer capped NPs over the larger PVP capped NPs is complemented by the differing recycling ability based on capping agent. Both results illustrate the effect of size and capping agent, which would not be possible if homogeneous catalysts were generated as the active species even if a "release and capture" dynamic were present. In a more rigorous test for the formation of a homogeneous species, a 3-phase test ${ }^{47,48}$ was employed with Wang resin-bound substrate $\mathbf{1 4}$ (Figure 6a). In the presence of homogeneous $\mathrm{PtCl}_{2}, 26 \%$ conversion of resin bound substrate to product was observed. However, both 2.9 $\mathrm{nm} \mathrm{Pt} / \mathrm{PVP} / \mathrm{SBA}-15$ and $\mathrm{Pt}_{40} / \mathrm{G} 4 \mathrm{OH} / \mathrm{SBA}-15$ oxidized with $\mathrm{PhICl}_{2}$ resulted in $<2 \%$ conversion. In addition, transmission electron microscopy (TEM) images of supported $\mathrm{Pt}_{40} / \mathrm{G} 4 \mathrm{OH} / \mathrm{SBA}-15 \mathrm{NPs}$ before and after reaction do not show any appreciable aggregation or leaching (Figure 6b). Furthermore, an experiment was conducted in which a $\mathrm{Pt}_{40} / \mathrm{G} 4 \mathrm{OH} / \mathrm{mesoporous} \mathrm{silica} \mathrm{pellet} \mathrm{was} \mathrm{used} \mathrm{to} \mathrm{allow} \mathrm{for}$ facile removal of the reaction solution from the NP catalyst under the reaction conditions and inert atmosphere. In this case, detailed in Figure $6 \mathrm{c}$, a solution of starting material, $\mathrm{PhICl}_{2}$ and solvent are added to the catalyst pellet in a reactor (A) and begin to generate product. After $42 \%$ yield is achieved, the reaction solution in $\mathbf{A}$ is transferred to a new vessel with no catalyst (B). The oxidized catalyst pellet 
remains in A. A fresh solution of starting material and solvent is then added into A. Now, the solution in $\mathbf{A}$ begins to convert to product while the solution in $\mathbf{B}$ does not react and remains at $42 \%$ yield. This further indicates the active catalyst is heterogeneous. If any homogeneous leached species were present, it would have also been transferred to $\mathbf{B}$ and an increase in yield would have been observed for the solution after it was removed from the heterogeneous catalyst pellet in A. Moreover, the new solution added to $\mathbf{A}$ begins to react, showing that the active catalyst has, in fact, remained in A. Finally, elemental analysis by inductively coupled plasma of a centrifuged solution (1 with $\mathrm{Pt}_{40} / \mathrm{G} 4 \mathrm{OH} / \mathrm{SBA}-15$ and $\mathrm{PhICl}_{2}$ in toluene) after reaction was unable to detect any significant amount (<1 ppm) of $\mathrm{Pt}$ above the instrument's detection limits. By the same analytical method, no loss of $\mathrm{Pt}$ was observed from the $\mathrm{Pt}$ to $/ \mathrm{G} 4 \mathrm{OH} / \mathrm{SBA}-15$ catalyst when it was isolated after the reaction. All together, this collection of experiments strongly indicates that no homogeneous catalytically active species had leached from the treated/oxidized $\mathrm{Pt}_{40} / \mathrm{G} 4 \mathrm{OH} / \mathrm{SBA}-15 \mathrm{NPs}$ during the reaction, and that the catalytically active species is the heterogeneous NP.

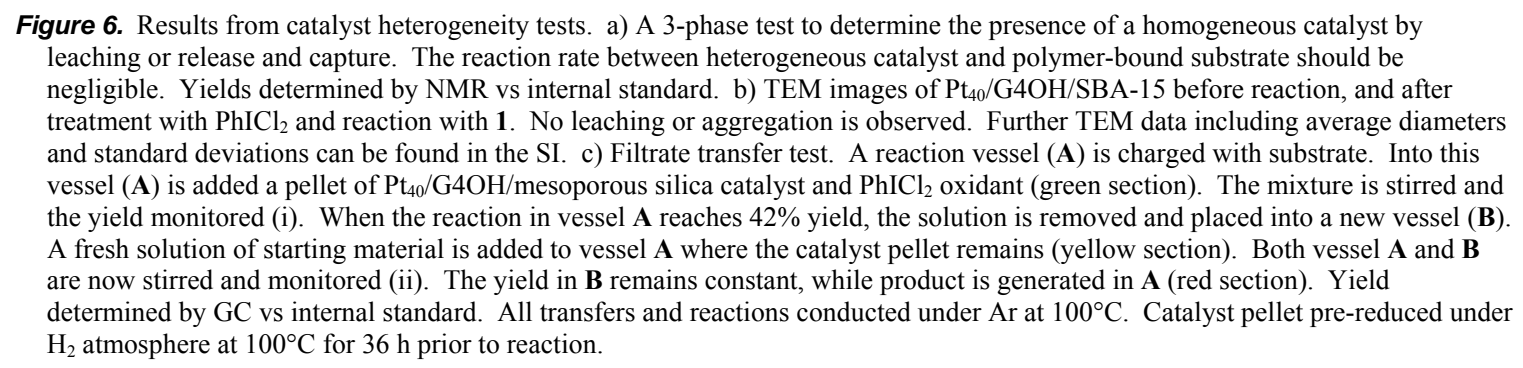

\section{Conclusion}

We have contributed to the larger goal of bridging the gap between homo- and heterogeneous catalysis with a strategy for developing catalytically active NPs capable of performing reactions previously in the exclusive purview of homogeneous chemistry. To this end, we have successfully identified novel electrophilic Pt NPs which catalyze a range of $\pi$-bond activation reactions with equivalent or superior yields and selectivities relative to reported homogeneous variants. Instrumental to this success were NP structural analyses and mechanistic insights that uncovered the importance of treatment with the hypervalent iodine oxidizing agent $\mathrm{PhICl}_{2}$. $\mathrm{Moreover}$ reaction kinetic analysis confirmed the capability of tuning nanoparticle size and capping agent to improve catalytic ability. Multiple experimental results indicate the heterogeneity of the dendrimer encapsulated NP catalyst supported on SBA-15. These discoveries, most notably the oxidative modification, illustrate the ability to obtain new reactivity from existing NP systems, and, in some cases, divergent reaction pathways are accessible. In a larger sense, this concept represents a significant advancement in the solution phase applications of supported NPs, and further application with other metals and treatment methods may facilitate the development of heterogeneous catalysts with novel activity or selectivity in an even larger array of chemical reactions. Efforts are underway to better understand the nature of the oxidation in order to further increase as well as maintain catalyst activity to allow for the development of a continuous flow system. Future studies can also move beyond traditional homogeneous ligand control and utilize NP shape or dendrimer composition to provide opportunities for selective solution-phase reactions.

\section{Methods}

\section{Synthesis of Nanoparticle Catalysts}

Dendrimer templated NPs

Generation 4 dendrimers $(\mathrm{G} 4 \mathrm{OH})$ were purchased from Dendritech Inc. (Midland, MI) as 10.2\% (mass) methanol solutions. A dendrimer stock solution $(250 \mu \mathrm{M})$ was prepared by adding water to the dendrimer methanol solution. The dendrimer stock solution was mixed with 15-40 mole equivalents of an aqueous solution of $0.01 \mathrm{M} \mathrm{K}_{2} \mathrm{PtCl}_{4}$ in a $20 \mathrm{~mL}$ vial. The vial was purged with Ar for $30 \mathrm{~min}$, tightly sealed with a septum and let sit for $66 \mathrm{~h}$ for complexation. Then a 20 -fold excess of freshly prepared $0.5 \mathrm{M} \mathrm{NaBH}_{4}$ (stored at $0^{\circ} \mathrm{C}$ before use) was injected dropwise into the vial with vigorous stirring. The reaction solution was then stirred for an additional $8 \mathrm{~h}$ after which, the reaction solution $(10 \mathrm{~mL})$ was purified by dialysis against $2 \mathrm{~L}$ of deionized water in cellulose dialysis sacks with a molecular weight cutoff of 12,000 (Sigma-Aldrich, Inc., St. Louis, MO). Dialysis occurred over $24 \mathrm{~h}$ with the water changed four times.

PVP capped NPs

Chloroplatinic acid $\left(\mathrm{H}_{2} \mathrm{PtCl}_{6} \cdot 6 \mathrm{H}_{2} \mathrm{O}, 99.9 \%\right.$ pure on metals basis) and polyvinylpyrrolidone (PVP) with a molecular weight of 29,000 were purchased from Sigma-Aldrich. 
For the synthesis of $1.5 \mathrm{~nm}$ Pt particles, $\mathrm{NaOH}$ was dissolved in ethylene glycol $(12.5 \mathrm{~mL}, 0.5 \mathrm{M})$. This solution was added to an ethylene glycol solution (12.5 mL) containing $\mathrm{H}_{2} \mathrm{PtCl}_{6} \cdot 6 \mathrm{H}_{2} \mathrm{O}(0.25 \mathrm{~g}, 0.48 \mathrm{mmol})$. During $\mathrm{N}_{2}$ purging, this combined solution was heated to $160^{\circ} \mathrm{C}$ and held for $3 \mathrm{~h}$. The resulting NPs were precipitated with $2 \mathrm{M} \mathrm{HCl}$ and dispersed in an ethanol/PVP mixture.

For the synthesis of $2.9 \mathrm{~nm}$ Pt particles, aqueous $\mathrm{H}_{2} \mathrm{PtCl}_{6} \cdot 6 \mathrm{H}_{2} \mathrm{O}(20 \mathrm{~mL}$ of $6.0 \mathrm{mM})$ was added into $180 \mathrm{~mL}$ of methanol. PVP (133 mg) was then dissolved in this mixture and refluxed for $3 \mathrm{~h}$.

For the synthesis of $5.0 \mathrm{~nm}$ Pt particles, freshly prepared $2.9 \mathrm{~nm}$ Pt particles were mixed in a $90 \%$ methanol $/ 10 \%$ water solution $(100 \mathrm{~mL})$. Methanol (90 $\mathrm{mL})$ and a solution of $\mathrm{H}_{2} \mathrm{PtCl}_{6} \cdot 6 \mathrm{H}_{2} \mathrm{O}(36.9 \mathrm{mg})$ in water $(10 \mathrm{~mL})$ were added and the combined mixture refluxed for $3 \mathrm{~h}$.

Mesoporous SBA-15 silica

Pluronic P123 (6.0 g, BASF) was dissolved in deionized water $(45 \mathrm{~g})$ and $2 \mathrm{M} \mathrm{HCl}(180 \mathrm{~g})$ while stirring at $35^{\circ} \mathrm{C}$ for $1 \mathrm{~h}$. Tetraethylorthosilicate (12.8 g, Sigma Aldrich, 98\%) was then added to the solution and allowed to stir for $20 \mathrm{~h}$. The mixture was then aged at $100^{\circ} \mathrm{C}$ for $24 \mathrm{~h}$. The mixture was filtered to give a white powder and further purified by washing with ethanol and deionized water. This purified product was dried in air at $100^{\circ} \mathrm{C}$ and then calcined at $550^{\circ} \mathrm{C}$ for $12 \mathrm{~h}$. The white powder was stored in a dessicator.

Preparation of Pt/SBA-15 catalysts

Pt NPs were loaded onto the mesoporous SBA-15 silica prior to the catalytic studies. SBA-15 was added to a colloidal solution of the Pt NPs and the resulting slurry was sonicated for $3 \mathrm{~h}$ at room temperature. The NP supported SBA-15 was separated from the solution by centrifuge at $4200 \mathrm{rpm}$ for 6 min. After centrifugation, the solution was clear. The solution was then decanted and the catalyst was dried under ambient conditions and then at $100^{\circ} \mathrm{C}$.

PVP encapsulated NPs were loaded to $1.0 \mathrm{wt} \%$ Pt. SBA-15 was used for 1.5 and $2.9 \mathrm{~nm}$ NPs. MCF-17 was used for $5.0 \mathrm{~nm}$ NPs. The larger size mesoporous silica was required for successful loading of the larger sized NPs.

Dendrimer encapsulated NPs were loaded to $0.7 \mathrm{wt} \%$ Pt. SBA- 15 was used as the support.

\section{Representative Procedure for Catalytic Reactions}

To a dry $10 \mathrm{~mL}$ glass reaction tube with stirbar and Teflon screwvalve cap under Ar was added 2-(phenylethynyl)phenol (1) (20 mg, $0.1025 \mathrm{mmol})$, $\mathrm{Pt}(2.9 \mathrm{~nm}) / \mathrm{PVP} / \mathrm{SBA}-15(50 \mathrm{mg}, 0.0026 \mathrm{mmol}, 2.5 \mathrm{~mol} \%), \mathrm{PhICl}_{2}(2.1 \mathrm{mg}, 0.0077 \mathrm{mmol}, 7.5 \mathrm{~mol} \%)$, mesitylene (15 $\mu \mathrm{L}$, internal standard, Aldrich) and toluene- $\mathrm{d}_{8}(2 \mathrm{~mL}$, Cambridge Isotopes). The reaction mixture was degassed (freeze/pump method) three times and placed under $1 \mathrm{~atm}$ of Ar. The reaction tube was sealed and the mixture heated with stirring to $100^{\circ} \mathrm{C}$ for 15 hours. The mixture was then cooled to rt and the solid catalyst filtered by glass microfiber filter. The filtrate was transferred to a NMR tube for analysis.

For the $\mathrm{Pt}_{40} / \mathrm{G} 4 \mathrm{OH} / \mathrm{SBA}-15$ catalyst, prior to addition of all other reaction materials, the catalyst was added to the dry $10 \mathrm{~mL}$ glass reaction tube and placed under $1 \mathrm{~atm}$ of $\mathrm{H}_{2}$. The catalyst was then heated to $100^{\circ} \mathrm{C}$ for 24 hours. After cooling to rt and replacing the $\mathrm{H}_{2}$ atmosphere with Ar, the reaction setup was continued as discussed above.

2-Phenylbenzofuran (2) can be isolated in the following manner. The toluene solution containing the product from the catalytic reaction was concentrated and purified by flash chromatography (5\% ethyl acetate/hexanes, Fisher ACS grade).

\section{References}

1. The $13^{\text {th }}$ International Symposium on Relations Between Homogeneous and Heterogeneous Catalysis. Zaera, F.; Joyner, R.W., Ed. Top Catal. 2008, 48.

2. Durán Pachón, L.; Rothenberg, G. Transition-Metal Nanoparticles: Synthesis, Stability and the Leaching Issue. Appl. Organometal. Chem. 2008, 22, 288.

3. Astruc, D.; Lu, F.; Ruiz Aranzaes, J.R. Nanoparticles as Recyclable Catalysts. The Frontier Between Homogeneous and Heterogeneous Catalysis. Angew. Chem. Int. Ed. 2005, 44, 7852 .

4. de Jesús, E.; Flores, J.C. Dendrimers: Solutions for Catalyst Separation and Recycling. Ind. Eng. Chem. Res. 2008, 47, 7968.

5. Kuhn, J.N.; Huang, W.; Tsung, C.-K.; Zhang, Y.; Somorjai, G.A. Structure Sensitivity of Carbon-Nitrogen Ring Opening: Impact of Platinum Particle Size from below 1 to $5 \mathrm{~nm}$ upon Pyrrole Hydrogenation Product Selectivity over Monodisperse Platinum Nanoparticles Loaded onto Mesoporous Silica. J. Am. Chem. Soc. 2008, 130, 14026.

6. Bhattacharjee, S.; Dotzauer, D.M.; Bruening, M.L. Selectivity as a Function of Nanoparticle Size in the Catalytic Hydrogenation of Unsaturated Alcohols. J. Am. Chem. Soc. 2009, 131, 3601.

7. Lee, I.; Delbecq, F.; Morales, R.; Albiter, M.A.; Zaera, F. Tuning Selectivity in Catalysis by Controlling Particle Shape. Nature Materials $2009,8,132$.

8. Tian, N.; Zhou, Z.-Y.; Sun, S.-G.; Ding, Y.; Wang, Z.L. Synthesis of Tetrahexahedral Platinum Nanocrystals with High-Index Facets and High Electrooxidation Activity. Science (Washington, D.C.) 2007, 316, 732.

9. Mahmoud, M.A.; Tabor, C.E.; El-Sayed, M.A.; Ding, Y.; Wang, Z.L. A New Catalytically Active Colloidal Platinum Nanocatalyst: the Multiarmed Nanostar Single Crystal. J. Am. Chem. Soc. 2008, 130, 4590.

10. Narayanan, R.; El-Sayed, M.A. Shape-Dependent Catalytic Activity of Platinum Nanoparticles in Colloidal Solution. Nano Lett. $2004,4,1343$.

11. Lee, H. et al. Morphological Control of Catalytically Active Platinum Nanocrystals. Angew. Chem. Int. Ed. 2006, $45,7824$.

12. Rioux, R.M.; et al. Monodisperse Platinum Nanoparticles of Well-Defined Shape: Synthesis, Characterization, Catalytic Properties and Future Prospects. Top. Catal. 2006, 39, 167.

13. Tsung, C.-K. et al. Sub-10 nm Platinum Nanocrystals with Size and Shape Control: Catalytic Study for Ethylene and Pyrrole Hydrogenation. J. Am. Chem. Soc. 2009, 131, 5816

14. Delbecq, F.; Zaera, F. Origin of the Selectivity for Trans-to-Cis Isomerization in 2-Butene on Pt(111) Single Crystal Surfaces. J. Am. Chem. Soc. 2008, $130,14924$.

15. Scott, R.W.J.; Wilson, O.M.; Crooks R.M. Synthesis, Characterization, and Applications of Dendrimer-Encapsulated Nanoparticles. J. Phys. Chem. B 2005, 109, 692 .

16. Narayanan, R.; Tabor, C.; El-Sayed, M.A. Can the Observed Changes in the Size or Shape of a Colloidal Nanocatalyst Reveal the Nanocatalysis Mechanism Type: Homogeneous or Heterogeneous? Top. Catal. 2008, 48, 60.

17. Bernechea, M.; de Jesús, E.; López-Mardomingo, C.; Terreros, P. Dendrimer-Encapsulated Pd Nanoparticles versus Palladium Acetate as Catalytic Precursors in the Stille Reaction in Water. Inorg. Chem. 2007, 48, 4491.

18. Zhang, X.; Corma, A. Supported Gold(III) Catalysts for Highly Efficient Three-Component Coupling Reactions. Angew. Chem. Int. Ed. 2008, 47, 4358.

19. Han, J.; Liu, Y.; Guo, R. Facile Synthesis of Highly Stable Gold Nanoparticles and Their Unexpected Excellent Catalytic Activity for Suzuki-Miyaura Cross-Coupling Reaction in Water. J. Am. Chem. Soc. 2009, 131, 2060.

20. Li, Y.; Hong, X.M.; Collard, D.M.; El-Sayed, M.A. Suzuki Cross-Coupling Reactions Catalyzed by Palladium Nanoparticles in Aqueous Solution. Org. Lett. 2000, 2, 2385

21. Djakovitch, L.; Köhler, K.; de Vries, J.G. The role of Palladium Nanoparticles as Catalysts for Carbon-Carbon Coupling Reactions. In Nanoparticles and Catalysis. Astruc, D., Ed.; Wiley-VCH: Weinheim, 2008, ch. 10, p. 303 and references therein.

22. Moreno-Maas, M.; Pleixats, R. Formation of Carbon-Carbon Bonds Under Catalysis by Transition-Metal Nanoparticles. Acc. Chem. Res. 2003, 36, 638.

23. Durand, J.; Teuma, E.; Gomez, M. An Overview of Palladium Nanocatalysts: Surface and Molecular Reactivity. Eur. J. Inorg. Chem. 2008, $23,3577$. 
24. Astruc, D. Palladium Nanoparticles as Efficient Green Homogeneous and Heterogeneous Carbon-Carbon Coupling Precatalysts: A Unifying View. Inorg. Chem. 2007, 46, 1884.

25. Thathagar, M.B.; ten Elshof, J.E.; Rothenberg, G. Pd Nanoclusters in C-C Coupling Reactions: Proof of Leaching. Angew. Chem. Int. Ed. 2006, 45, 2886.

26. Crooks, R.M.; Mingqi, Z.; Sun, L.; Checkhik, V.; Yeung, L.K. Dendrimer-Encapsulated Metal Nanoparticles: Synthesis, Characterization, and Applications to Catalysis. Acc. Chem. Res. 2001, 34, 181.

27. Rioux, R.M.; Song, H.; Hoefelmeyer, J.D.; Yang, P.; Somorjai, G.A. High-Surface-Area Catalyst Design: Synthesis, Characterization, and Reaction Studies of Platinum Nanoparticles in Mesoporous SBA-15 Silica. J. Phys. Chem. B 2005, 109, 2192.

28. Huang, W. et al. Dendrimer Templated Synthesis of One Nanometer Rh and Pt Particles Supported on Mesoporous Silica: Catalytic Activity for Ethylene and Pyrrole Hydrogenation. Nano Lett. 2008, 8, 2027.

29. Fürstner, A.; Davies, P.W. Heterocycles by $\mathrm{PtCl}_{2}$-Catalyzed Intramolecular Carboalkoxylation or Carboamination of Alkynes. J. Am. Chem. Soc. 2005, $127,15024$.

30. Knecht, M.R. et al. Synthesis and Characterization of Pt Dendrimer-Encapsulated Nanoparticles: Effect of the Template on Nanoparticle Formation. Chem. Mater. 2008, 20, 5218 .

31. Ozturk, O. et al. Thermal Decomposition of Generation-4 Polyamidoamine Dendrimer Films: Decomposition Catalyzed by Dendrimer-Encapsulated Pt Particles. Langmuir 2005, 21, 3998

32. Ye, H.; Scott, R.W.J.; Crooks, R.M. Synthesis, Characterization, and Surface Immobilization of Platinum and Palladium Nanoparticles Encapsulated within Amine-Terminated Poly(amidoamine) Dendrimers. Langmuir 2004, 20, 2915.

33. Doná, E. et al. Halogen-Induced Corrosion of Platinum. J. Am. Chem. Soc. 2009, 131, 2827.

34. Whitfield, S.R.; Sanford, M.S. Reactivity of Pd(II) Complexes with Electrophilic Chlorinating Reagents: Iisolation of Pd(IV) Products and Observation of C-Cl Bond-Forming Reductive Elimination. J. Am. Chem. Soc. 2007, 129, 15142.

35. Li, Y.; El-Sayed, M.A. The Effect of Stabilizers on the Catalytic Activity and Stability of Pd Colloidal Nanoparticles in the Suzuki Reactions in Aqueous Solution. J. Phys. Chem. B 2001, 105, 8938.

36. Deutsch, D. S. et al. FT-IR Investigation of the Thermal Decomposition of Poly(amidoamine) Dendrimers and Dendrimer-Metal Nanocomposites supported on $\mathrm{Al}_{2} \mathrm{O}_{3}$ and $\mathrm{ZrO}_{2}$. J. Phys. Chem. C 2007, 111, 4246.

37. Lang, H.; May, R.A.; Iversen, B.L.; Chandler, B.D. Dendrimer-Encapsulated Nanoparticle Precursors to Supported Platinum Catalysts. J. Am. Chem. Soc. 2003, 125, 14832 .

38. Cai, W.; Zhong, H.; Zhang, L. Optical Measurements of Oxidation Behavior of Silver Nanometer Particle within Pores of Silica Host. J. Appl. Phys. 1998, 83, 1705

39. Smithells Metal Reference Book. $6^{\text {th }}$ Ed.; Brandes, E.A., Ed.; London; Boston: Butterworths, 1983

40. Bond, G.C. Supported Metal Catalysts: Some unsolved problems. Chem. Soc. Rev. 1991, 20, 441.

41. LaLonde, R.L.; Sherry, B.D.; Kang, E.J.; Toste, F.D. Gold(I)-Catalyzed Enantioselective Intramolecular Hydroamination of Allenes. J. Am. Chem. Soc. 2007, 129, 2452.

42. Barluenga, J.; Trincado, M.; Rubio, E.; González, J.M. $\mathrm{IPy}_{2} \mathrm{BF}_{4}$-Promoted Intramolecular Addition of Masked and Unmasked Anilines to Alkynes: Direct Assembly of 3-Iodoindole Cores. Angew. Chem. Int. Ed. 2003, 42, 2406.

43. Fürstner, A.; Mamane, V. Flexible Synthesis of Phenanthrenes by a $\mathrm{PtCl}_{2}$-Catalyzed Cycloisomerization Reaction. J. Org. Chem. 2002, 67, 6264 .

44. Nakamura, I.; Sato, Y.; Terada, M. Platinum-Catalyzed Dehydroalkoxylation-Cyclization Cascade via N-O Bond Cleavage. J. Am. Chem. Soc. 2009, $131,4198$.

45. Yeung, L.K.; Lee, C.T., Jr.; Johnston, K.P.; Crooks, R.M. Catalysis in Supercritical $\mathrm{CO}_{2}$ Using Dendrimer-Encapsulated Palladium Nanoparticles. Chem. Comm. 2001, 21, 2290.

46. Ooe, M.; Murata, M.; Mizugaki, T.; Ebitani, K.; Kaneda, K.. Supramolecular Catalysts by Encapsulating Palladium Complexes within Dendrimers. J. Am. Chem. Soc. 2004, 126, 1604.

47. Davies, I.W.; Matty, L.; Hughes, D.L.; Reider, P.J. Are Heterogeneous Catalysts Precursors to Homogeneous Catalysts? J. Am. Chem. Soc. 2001, 123, 10139.

48. Dahan, A.; Portnoy, M. Pd Catalysis on Dendronized Solid Support: Generation Effects and the Influence of the Backbone Structure. J. Am. Chem. Soc. 2007, 129, 5860 .

\section{Acknowledgements}

We acknowledge support from the Director, Office of Science, Office of Basic Energy Sciences, Division of Chemical Sciences, Geological and Biosciences of the U.S. DOE under Contract DE-AC03-76SF00098 and the Director, Office of Science, Office of Basic Energy Sciences, Division of Materials Sciences and Engineering of the U.S. DOE under Contract No. DE-AC02-05CH11231.

\section{Author Contributions}

C.A.W, W.H., C.-K.T. and J.N.K. performed the experiments and synthesized materials, substrates and catalysts. F.D.T. and G.A.S supervised the research. All authors contributed to the conception of the experiments, discussed the results and commented on the manuscript.

\section{Additional Information}

Supplementary information and chemical compound information accompany this paper at www.nature.com/naturechemistry. Reprints and permission information is available online at http://npg.nature.com/reprintsandpermissions/. Correspondence and requests for materials should be addressed to F.D.T. 
Figure 1

a

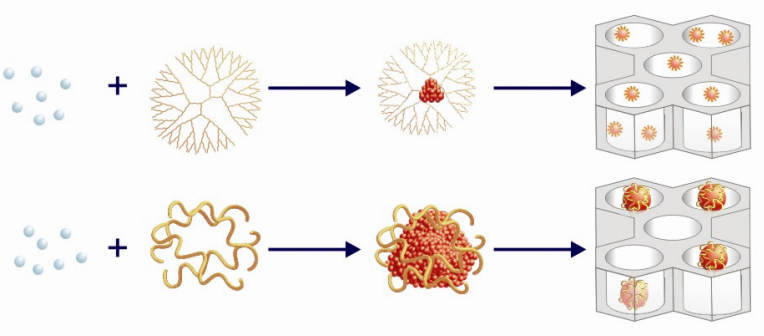

b

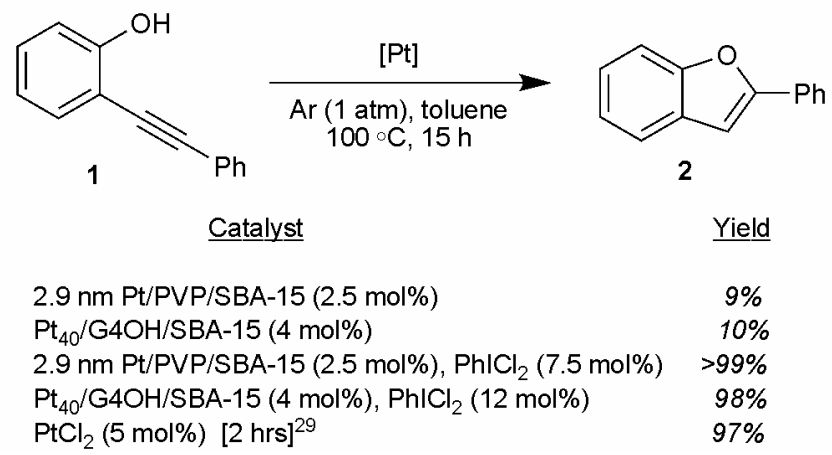

Figure 2

a

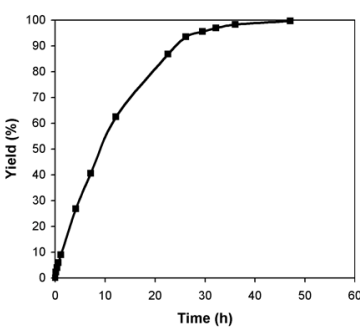

c

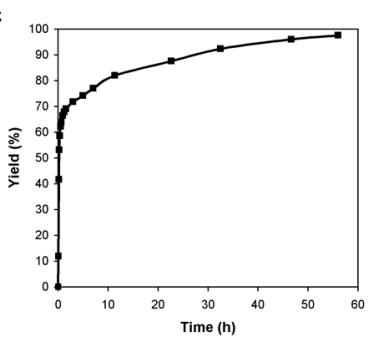

b

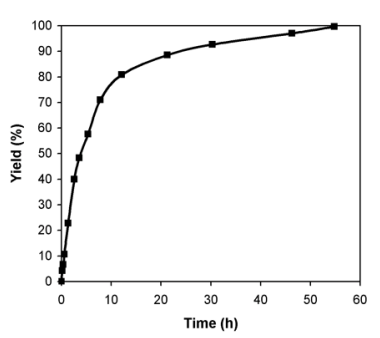

d

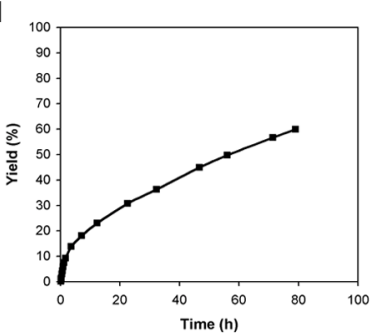


Figure 3

a<smiles>CC(=O)Nc1ccccc1C#Cc1ccccc1</smiles>

b

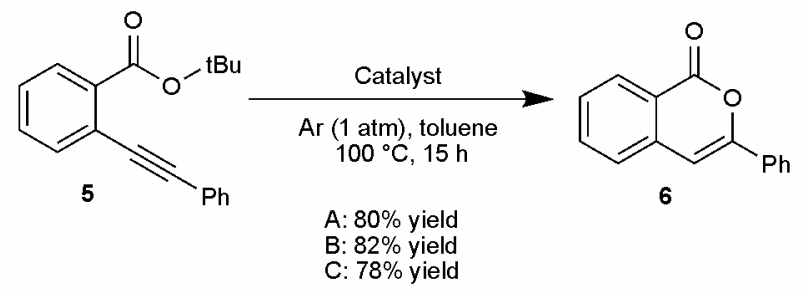

c

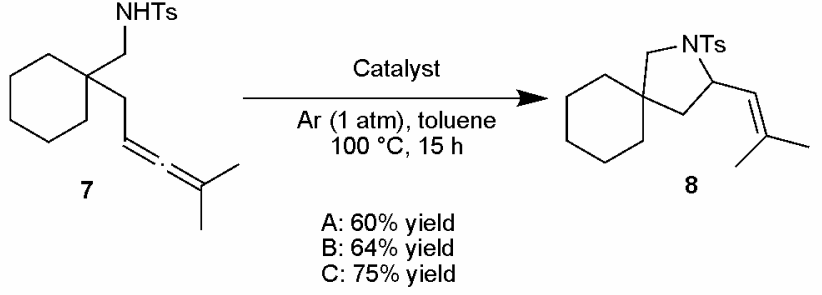

d

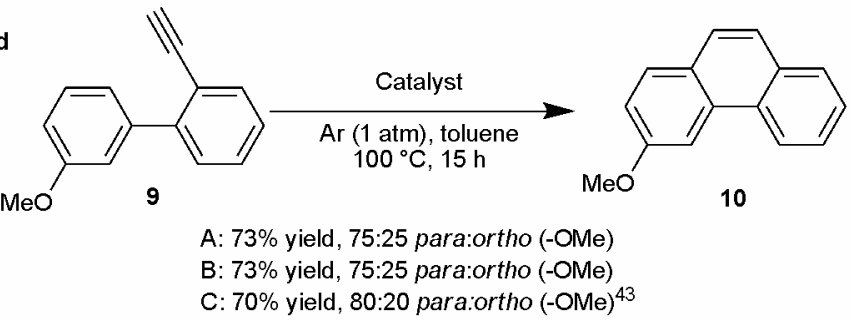

Figure 4<smiles>Oc1ccccc1C#Cc1ccccc1</smiles>

$\mathrm{Pd}_{40} / \mathrm{G} 4 \mathrm{OH} / \mathrm{SBA}-15$ (4 mol\%)

$\mathrm{Pd}_{40} / \mathrm{G} 4 \mathrm{OH} / \mathrm{SBA}-15$ (4 mol\%), $\mathrm{PhICl}_{2}$ (12 mol\%)

$\mathrm{PdCl}_{2}$ (4 mol\%)

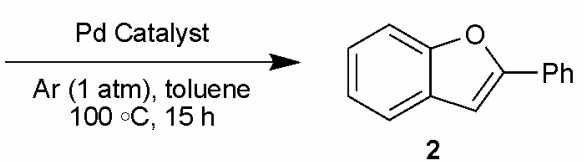

$10 \%$ yield

$48 \%$ yield

$50 \%$ yield 
Figure 5

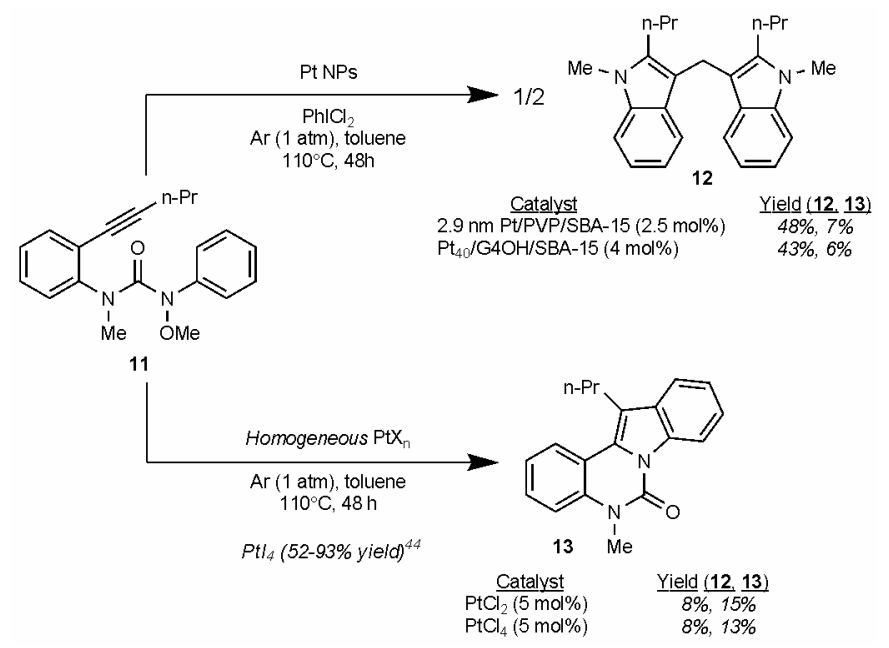

Figure 6

a

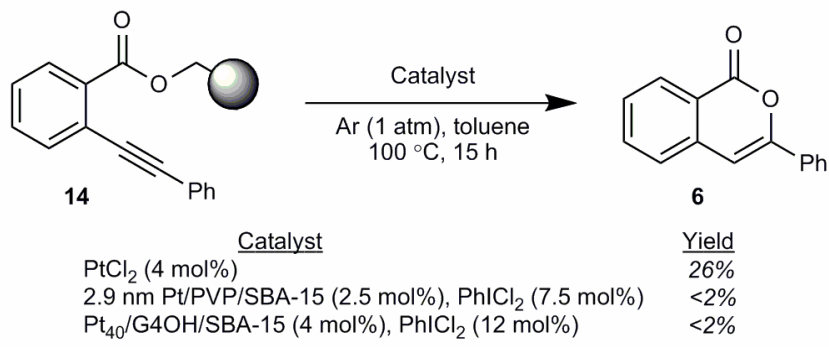

b

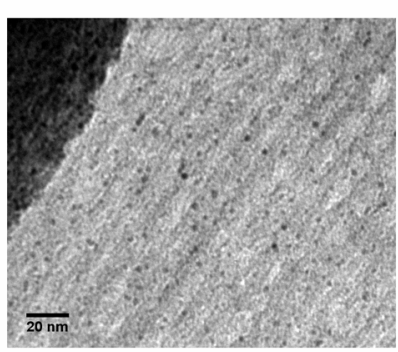

(before)

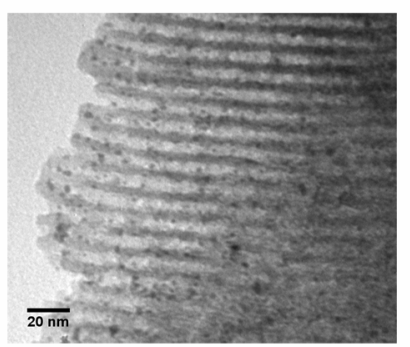

(after) 
C
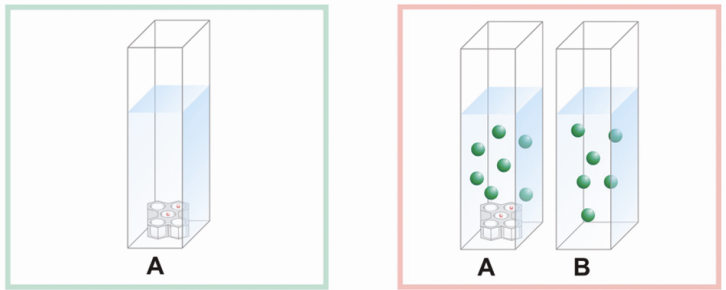

i $\downarrow$

ii $\uparrow$

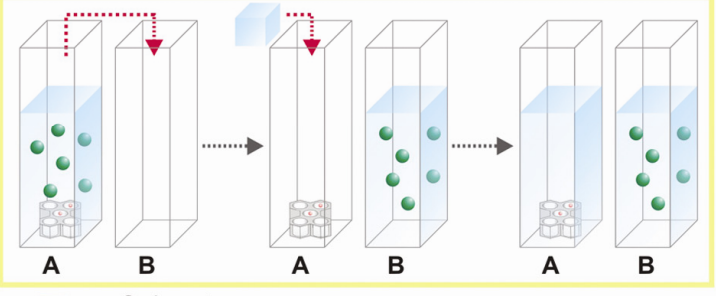

Solvent +

B

$=$ Reactant

Iifi $=$ Pellet Catalyst $\quad=$ Product

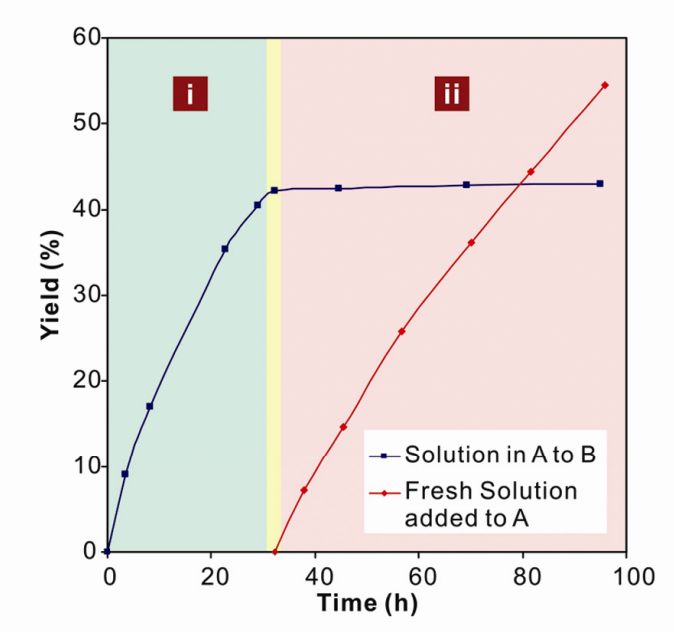




\section{Supporting Information}

\section{Converting Homogeneous to Heterogeneous in Electrophilic Catalysis Using Monodisperse Metal Nanoparticles}

Cole A. Witham, Wenyu Huang, Chia-Kuang Tsung, John N. Kuhn, Gabor A. Somorjai, F. Dean Toste Department of Chemistry, University of California, Berkeley, CA, and Chemical and Materials Sciences Divisions, Lawrence Berkeley National Laboratory, 1 Cyclotron Road, Berkeley, CA 94720

General Information. Unless otherwise noted, all commercial materials were used without further purification. Triethylamine was purified by passing through a column of alumina under argon. Unless otherwise noted, all other solvents were used as received. $\mathrm{PhICl}_{2}$ was prepared according to the method of Skulski et al. ${ }^{1}$

TLC analysis of reaction mixtures was performed on Merck silica gel $60 \mathrm{~F}_{254}$ TLC plates. Flash chromatography was carried out on Sorbent Technologies 40-63 D $60 \AA$ silica gel. ${ }^{1} \mathrm{H}$ and ${ }^{13} \mathrm{C}$ NMR spectra were recorded with Bruker AVB-400, AV-500, DRX-500 or AV-600 spectrometers and were referenced to residual ${ }^{1} \mathrm{H}$ and ${ }^{13} \mathrm{C}$ signals of the deuterated solvents relative to TMS, respectively. GC-MS data were obtained via a HP 8690 Series Gas Chromatograph with a 5973 Series Mass Selective Detector. IR spectra were recorded on a Nicolet MAGNA-IR 850 spectrometer as thin films on a $\mathrm{NaCl}$ disc. High resolution mass spectral data were obtained via the Micro-Mass/Analytical Facility operated by the College of Chemistry, University of California at Berkeley. ICP-MS data were obtained via Galbraith Laboratories, Inc., Knoxville, TN. Sonication was performed on a VWR ultrasonic cleaner, 75T, $120 \mathrm{~W}$, $45 \mathrm{kHz}$. Centrifugation was performed on a Thermo Scientific IEC Centra ${ }^{\circledR}$ CL2.

\section{Synthesis of Nanoparticle Catalysts.}

\section{Dendrimer templated NPs}

Dendrimer encapsulated NPs were synthesized following previously published methods ${ }^{2}$ with some modifications. ${ }^{3}$ Generation 4 dendrimers $(\mathrm{G} 4 \mathrm{OH})$ were purchased from Dendritech Inc. (Midland, MI) as $10.2 \%$ (mass) methanol solutions. A dendrimer stock solution $(250 \mu \mathrm{M})$ was prepared by adding water to the dendrimer methanol solution. The dendrimer stock solution was mixed with 15-40 mole equivalents of an aqueous solution of $0.01 \mathrm{M} \mathrm{K}_{2} \mathrm{PtCl}_{4}$ in a $20 \mathrm{~mL}$ vial. The vial was purged with $\mathrm{Ar}$ for $30 \mathrm{~min}$, tightly sealed with a septum and let sit for $66 \mathrm{~h}$ for complexation. Then a 20-fold excess of freshly prepared $0.5 \mathrm{M} \mathrm{NaBH}_{4}$ (stored at $0^{\circ} \mathrm{C}$ before use) was injected dropwise into the vial with vigorous stirring. The reaction solution was then stirred for an additional $8 \mathrm{~h}$ after which, the reaction solution (10 
$\mathrm{mL}$ ) was purified by dialysis against $2 \mathrm{~L}$ of deionized water in cellulose dialysis sacks with a molecular weight cutoff of 12,000 (Sigma-Aldrich, Inc., St. Louis, MO). Dialysis occurred over $24 \mathrm{~h}$ with the water changed four times.

\section{PVP capped NPs}

The Pt NPs capped by PVP were synthesized using established methods. ${ }^{4-7}$ Chloroplatinic acid $\left(\mathrm{H}_{2} \mathrm{PtCl}_{6} \cdot 6 \mathrm{H}_{2} \mathrm{O}, 99.9 \%\right.$ pure on metals basis) and polyvinylpyrrolidone (PVP) with a molecular weight of 29,000 were purchased from Sigma-Aldrich.

For the synthesis of $1.5 \mathrm{~nm}$ Pt particles, $\mathrm{NaOH}$ was dissolved in ethylene glycol $(12.5 \mathrm{~mL}, 0.5 \mathrm{M})$. This solution was added to an ethylene glycol solution (12.5 mL) containing $\mathrm{H}_{2} \mathrm{PtCl}_{6} \cdot 6 \mathrm{H}_{2} \mathrm{O}(0.25 \mathrm{~g}, 0.48$ $\mathrm{mmol}$ ). During $\mathrm{N}_{2}$ purging, this combined solution was heated to $160^{\circ} \mathrm{C}$ and held for $3 \mathrm{~h}$. The resulting NPs were precipitated with $2 \mathrm{M} \mathrm{HCl}$ and dispersed in an ethanol/PVP mixture.

For the synthesis of $2.9 \mathrm{~nm}$ Pt particles, aqueous $\mathrm{H}_{2} \mathrm{PtCl}_{6} \cdot 6 \mathrm{H}_{2} \mathrm{O}(20 \mathrm{~mL}$ of $6.0 \mathrm{mM})$ was added into $180 \mathrm{~mL}$ of methanol. PVP $(133 \mathrm{mg})$ was then dissolved in this mixture and refluxed for $3 \mathrm{~h}$.

For the synthesis of $5.0 \mathrm{~nm}$ Pt particles, freshly prepared $2.9 \mathrm{~nm}$ Pt particles were mixed in a $90 \%$ methanol/10\% water solution (100 mL). Methanol $(90 \mathrm{~mL})$ and a solution of $\mathrm{H}_{2} \mathrm{PtCl}_{6} \cdot 6 \mathrm{H}_{2} \mathrm{O}(36.9 \mathrm{mg})$ in water $(10 \mathrm{~mL})$ were added and the combined mixture refluxed for $3 \mathrm{~h}$.

\section{Mesoporous SBA-15 silica}

Mesoporous SBA-15 silica was prepared utilizing the conventional method. ${ }^{8}$ Pluronic P123 (6.0 g, BASF) was dissolved in deionized water $(45 \mathrm{~g})$ and $2 \mathrm{M} \mathrm{HCl}(180 \mathrm{~g})$ while stirring at $35^{\circ} \mathrm{C}$ for $1 \mathrm{~h}$. Tetraethylorthosilicate (12.8 g, Sigma Aldrich, 98\%) was then added to the solution and allowed to stir for $20 \mathrm{~h}$. The mixture was then aged at $100^{\circ} \mathrm{C}$ for $24 \mathrm{~h}$. The mixture was filtered to give a white powder and further purified by washing with ethanol and deionized water. This purified product was dried in air at $100^{\circ} \mathrm{C}$ and then calcined at $550^{\circ} \mathrm{C}$ for $12 \mathrm{~h}$. The white powder was stored in a dessicator.

\section{Mesoporous MCF-17 silica}

The synthesis of MCF-17 followed the previous reports. ${ }^{9,10}$ 1,3,5-trimethylbenzene (4 g) was added to a solution containing triblockcopolymer Pluronic P123 (4 g), $\mathrm{HCl}$ (conc., $10 \mathrm{~mL}$ ) and deionized water $(75 \mathrm{~mL})$. The solution was stirred at $40^{\circ} \mathrm{C}$ for $2 \mathrm{~h}$ after which tetraethoxysilane $(9.2 \mathrm{~mL})$ was added. After stirring for $5 \mathrm{~min}$, the solution was aged at $40^{\circ} \mathrm{C}$ for $20 \mathrm{~h}$ with no stirring. Then, $\mathrm{NH}_{4} \mathrm{~F}(46 \mathrm{mg})$ was added to the solution. This solution was transferred to an autoclave and aged at $100^{\circ} \mathrm{C}$ for an additional $24 \mathrm{~h}$. The precipitate formed was filtered, washed with deionized water and ethanol and calcined in air at $550^{\circ} \mathrm{C}$ for $6 \mathrm{~h}$. The white powder obtained was stored in a dessicator. 


\section{Preparation of Pt/SBA-15 catalysts}

Pt NPs were loaded onto the mesoporous SBA-15 silica prior to the catalytic studies. SBA-15 was added to a colloidal solution of the Pt NPs and the resulting slurry was sonicated for $3 \mathrm{~h}$ at room temperature. The NP supported SBA-15 was separated from the solution by centrifuge at $4200 \mathrm{rpm}$ for 6 min. After centrifugation, the solution was clear. The solution was then decanted and the catalyst was dried under ambient conditions and then at $100^{\circ} \mathrm{C}$.

PVP encapsulated NPs were loaded to $1.0 \mathrm{wt} \%$ Pt. SBA-15 was used for 1.5 and $2.9 \mathrm{~nm}$ NPs. MCF17 was used for $5.0 \mathrm{~nm}$ NPs. The larger size mesoporous silica was required for successful loading of the larger sized NPs.

Dendrimer encapsulated NPs were loaded to $0.7 \mathrm{wt} \% \mathrm{Pt}$. SBA-15 was used as the support.

\section{Preparation of Pt/mesoporous silica pellet catalyst}

For a typical synthesis, P123 ( $1 \mathrm{~g}, \mathrm{MW}=5800$, Aldrich) was dissolved in a mixture with ethanol $(5 \mathrm{~g})$ and $\mathrm{HCl}(0.2 \mathrm{~g}$, aqueous, $1 \mathrm{M})$, and stirred until a homogeneous solution formed. While the mixture was still stirring, TEOS ( $2.08 \mathrm{~g}$ ) was added to the solution, and the mixture was further stirred for $10 \mathrm{~min}$. The solution derived above was then transferred into a ceramic vessel and aged at room temperature for $36 \mathrm{~h}$ in air. Then the silica gel was covered with a layer of liquid paraffin in 2-3-mm thickness and heated at 60 ${ }^{\circ} \mathrm{C}$ for $18 \mathrm{~h}$ to remove the ethanol completely. The residue liquid paraffin on the surface of the products was removed and cleared by using filter paper. For the removal of the block copolymer, calcination was carried out in an oven at $550{ }^{\circ} \mathrm{C}$ in air for $6 \mathrm{~h}^{11}$

For loading the nanoparticles onto the pellet, a $\mathrm{Pt}_{40}$ colloidal solution $(10 \mathrm{~mL})$ was concentrated to 1 $\mathrm{mL}$ by rotovap at $50^{\circ} \mathrm{C}$. The solution was added the pellet of mesoporous support and sonicated for $3 \mathrm{~h}$ at rt. The pellet solution was then evaporated at $50^{\circ} \mathrm{C}$ and the remaining solid was further dried at $100^{\circ} \mathrm{C}$ for $24 \mathrm{~h}$.

\section{TEM of Pt NPs and Pt/SBA-15 catalysts}

Pt NPs were imaged by TEM using a FEI Tecnai G2 S-Twin electron microscope at an accelerating voltage of $200 \mathrm{kV}$. A representative TEM image of the dendrimer capped $\mathrm{Pt}_{40} \mathrm{NPs}$ is shown in the insert of Figure S1a. After counting more than 300 NPs, the size distribution of the NPs is shown in Figure S1a. The averaged size of the nanoparticle is $1.1 \pm 0.3 \mathrm{~nm}$. The averaged diameter of the NPs agrees with calculated size for a 40 atoms Pt cluster assuming a spherical shape $(1.05 \mathrm{~nm})$. For the PVP capped 2.9 $\mathrm{nm}$ Pt NPs, the size distribution is shown in Figure S1b (diameter is $2.9 \pm 0.5 \mathrm{~nm}$ ). The insert in Figure $\mathrm{S} 1 \mathrm{~b}$ is a representative TEM image for the $2.9 \mathrm{~nm}$ Pt NPs. 

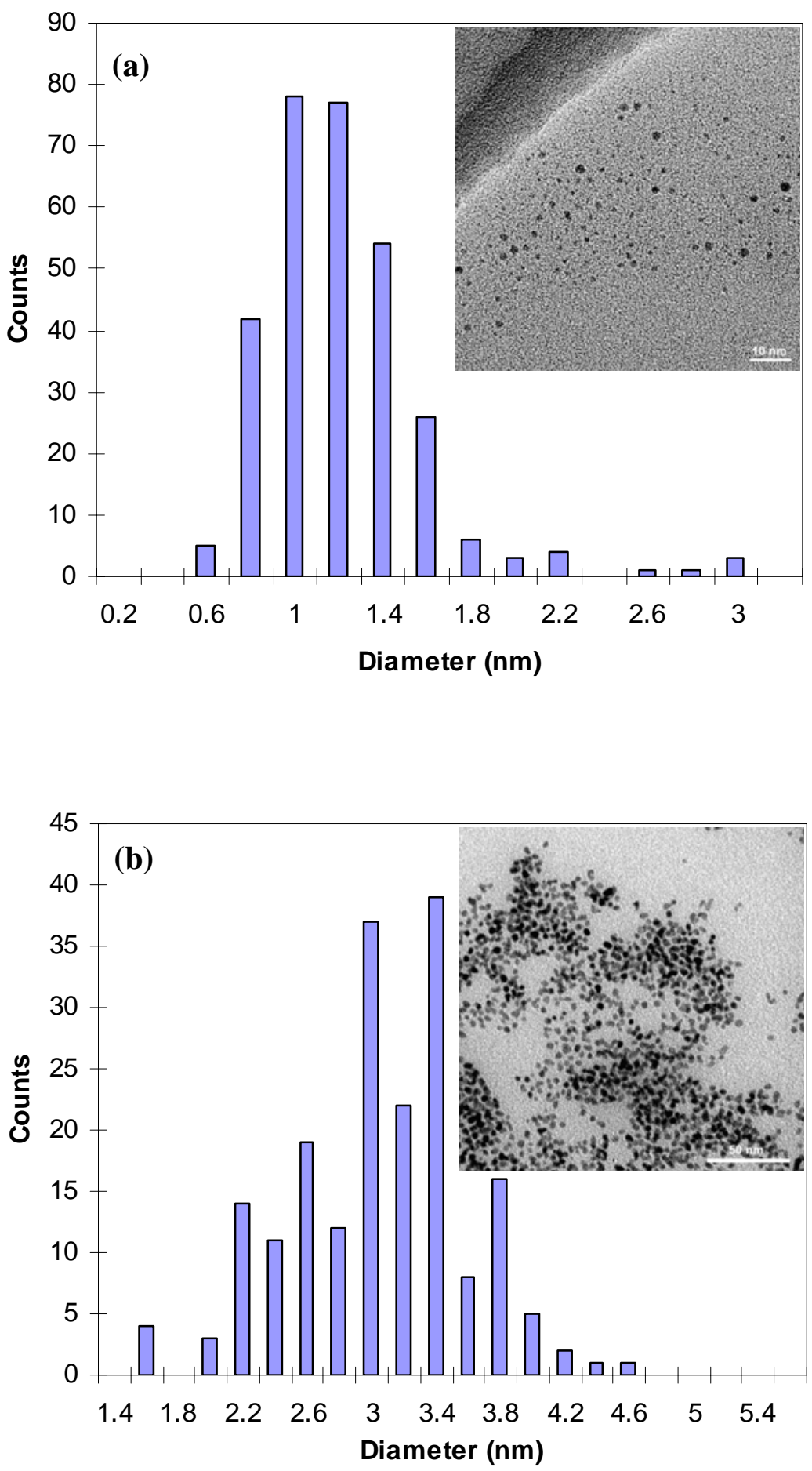

Figure S1. Metal particle size distributions obtained by TEM measurements of (a) dendrimer capped $\mathrm{Pt}_{40}$ NPs and (b) PVP capped $2.9 \mathrm{~nm}$ Pt NPs. Inserts in (a) and (b) are representative TEM images of $\mathrm{Pt}_{40}$ and $2.9 \mathrm{~nm}$ Pt NPs, respectively. 


\section{Characterization of Pt/SBA-15 NP catalysts}

Characterization results for the dendrimer and PVP capped NPs have been published previously.,12

\section{Degradation of PAMAM dendrimer}

It is possible that, under the reaction conditions, the dendrimer could decompose. However, the similar, reproducible catalytic activity of the $\mathrm{Pt}_{40} / \mathrm{G} 4 \mathrm{OH} / \mathrm{SBA}-15 \mathrm{NP}$ catalyst after recycling, and its divergence from that observed for the PVP capping agent both before and after recycling suggests its continued presence. Furthermore, no aggregation or leaching of the NPs are observed during/after reaction. Recent reports that suggest more harsh conditions are required for complete dendrimer removal. ${ }^{13,14,15}$ Regardless, if decomposition of the dendrimer is occurring, it does not appear to alter the catalytic activity. For the purposes of this manuscript we will include the capping agent of the nanoparticles in their names as a reference to their origin and initial state.

\section{Synthesis of Pd NPs}

Pd NPs ${ }^{16,17}$ were made following the same procedure as Pt with the following exceptions: 1) The dendrimer stock solution was mixed with 15-40 mole equivalents of an aqueous solution of 0.01 $\mathrm{M}$ $\boldsymbol{K}_{2} \mathbf{P d C l} \boldsymbol{l}_{4}$ in a $20 \mathrm{~mL}$ vial. The vial was purged with Ar for $30 \mathrm{~min}$, tightly sealed with a septum and let sit for $1 \boldsymbol{h}$ for Pd complexation. 2) For the sysnthesis of the dendrimer templated NPs, the reaction solution was then stirred for an additional $\mathbf{1} \boldsymbol{h}$ after which, the reaction solution $(10 \mathrm{~mL})$ was purified by dialysis against $2 \mathrm{~L}$ of deionized water in cellulose dialysis sacks with a molecular weight cutoff of 12,000 (Sigma-Aldrich, Inc., St. Louis, MO). 3) Dendrimer encapsulated NPs were loaded to $0.3 \mathbf{w t} \% \mathbf{P d}$. SBA15 was used as the support.

\section{Preparation and Characterization of Organic Substrates and Products}

Preparation of 1

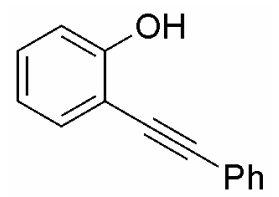

2-(Phenylethynyl)phenol (1) was prepared by the Pd catalyzed reaction of methoxymethyl protected 2-iodophenol with phenylacetylene followed by deprotection. Spectral data were consistent with the values previously reported. ${ }^{18}{ }^{1} \mathrm{H}$ NMR $\left(\mathrm{CDCl}_{3}, 500 \mathrm{MHz}\right): \delta 5.87(\mathrm{~s}, 1 \mathrm{H}), 6.94(\mathrm{td}, 1 \mathrm{H}, J=0.8$ and $7.5 \mathrm{~Hz}), 7.01(\mathrm{~d}, 1 \mathrm{H}, J=8.0 \mathrm{~Hz}), 7.30(\mathrm{t}, 1 \mathrm{H}, J=7.5 \mathrm{~Hz}), 7.39-7.42(\mathrm{~m}, 3 \mathrm{H}), 7.45(\mathrm{dd}, 1 \mathrm{H}, J=1.5$ and 8.0), 7.55-7.59 (m, 2H). 


\section{Characterization of 2}<smiles>c1ccc(-c2cc3ccccc3o2)cc1</smiles>

2-Phenylbenzofuran (2) was identified by comparison to published characterization data. Spectral data were consistent with the values previously reported. ${ }^{18}{ }^{1} \mathrm{H} \mathrm{NMR}\left(\mathrm{CDCl}_{3}, 500 \mathrm{MHz}\right): \delta 7.06(\mathrm{~s}, 1 \mathrm{H})$, 7.23-7.33 (m, 2H), 7.38 (t, 1H, J = 7.5 Hz), 7.48 (t, 2H, J=7.3 Hz), 7.55 (d, 1H, J = 8.2 Hz), 7.61 (d, 1H, $J=7.8 \mathrm{~Hz}), 7.89(\mathrm{~d}, 2 \mathrm{H}, J=7.0 \mathrm{~Hz})$.

\section{Preparation of 3}<smiles>CC(=O)Nc1ccccc1C#Cc1ccccc1</smiles>

To a dry flask containing 2-iodoaniline $(2.65 \mathrm{~g}, 13.7 \mathrm{mmol}$, Aldrich) was added pyridine (30 $\mathrm{mL}$, EMD Drisolv $\left.{ }^{\circledR}\right)$ and methyl chloroformate $\left(2 \mathrm{~mL}, 25.9 \mathrm{mmol}\right.$, Aldrich) under Ar at $0^{\circ} \mathrm{C}$. The reaction mixture was stirred and warmed to room temperature, then allowed to stir for an additional $12 \mathrm{~h}$. At this point, TLC analysis indicated complete consumption of starting material and $\mathrm{HCl}(30 \mathrm{~mL}, 1 \mathrm{M})$ was added to the reaction solution. The resulting mixture was extracted with $\mathrm{CH}_{2} \mathrm{Cl}_{2}(3 \times 15 \mathrm{~mL}$, Fisher HPLC grade). The combined organic layers were dried with $\mathrm{MgSO}_{4}$, filtered and concentrated. Pyridine was removed by toluene azeotrope with a rotary evaporator. The resulting methyl 2-iodophenylcarbamate ( $3.63 \mathrm{~g}, 96 \%$, pale yellow solid) was used in the next step without further purification. ${ }^{1} \mathrm{H} \mathrm{NMR}\left(\mathrm{CDCl}_{3}\right.$, $400 \mathrm{MHz}) \delta 3.85(\mathrm{~s}, 3 \mathrm{H}), 6.85(\mathrm{td}, 1 \mathrm{H}, J=1.6$ and $7.6 \mathrm{~Hz}), 7.01($ br s, $1 \mathrm{H}), 7.38(\mathrm{t}, 1 \mathrm{H}, J=7.2 \mathrm{~Hz}), 7.80$ (dd, $1 \mathrm{H}, J=1.2$ and $7.6 \mathrm{~Hz}), 8.10(\mathrm{~d}, 1 \mathrm{H}, J=8.0 \mathrm{~Hz})$.

To a dry flask containing dry, degassed triethylamine $(20 \mathrm{~mL})$ was added methyl 2iodophenylcarbamate $(2 \mathrm{~g}, 7.23 \mathrm{mmol})$ and phenylacetylene $(872 \mu \mathrm{L}, 7.94 \mathrm{mmol}$, Aldrich) under Ar. Then, $\mathrm{Pd}\left(\mathrm{PPh}_{3}\right)_{4}\left(166 \mathrm{mg}, 0.14 \mathrm{mmol}, 2 \mathrm{~mol} \%\right.$, Strem) and freshly prepared CuI ${ }^{19}$ (69 mg, $0.36 \mathrm{mmol}, 5$ mol\%) was added. The mixture was then stirred for $12 \mathrm{~h}$ in the dark under Ar. The reaction mixture was filtered through a plug of silica and the plug was washed with $\mathrm{Et}_{2} \mathrm{O}(\sim 100 \mathrm{~mL}$, Fisher Anhydrous ACS grade). The filtrate was concentrated and purified by flash chromatography (10\% ethyl acetate/hexanes, Fisher ACS grade) to afford methyl 2-(phenylethynyl)phenylcarbamate (3) as a yellow solid (1.77g, 7.05 mmol, 98\%). ${ }^{1} \mathrm{H} \mathrm{NMR}\left(\mathrm{CDCl}_{3}, 500 \mathrm{MHz}\right): \delta 3.816(\mathrm{~s}, 3 \mathrm{H}), 7.04(\mathrm{t}, 1 \mathrm{H}, J=7.5 \mathrm{~Hz}), 7.34-7.40(\mathrm{~m}, 4 \mathrm{H})$, $7.48(\mathrm{dd}, 2 \mathrm{H}, J=1.5$ and $7.5 \mathrm{~Hz}), 7.56(\mathrm{dd}, 2 \mathrm{H}, J=2.5$ and $7.5 \mathrm{~Hz}), 8.18(\mathrm{~d}, 1 \mathrm{H}, J=8.0 \mathrm{~Hz}) .{ }^{13} \mathrm{C} \mathrm{NMR}$ $\left(\mathrm{CDCl}_{3}, 125 \mathrm{MHz}\right): \delta 52.4,84.1,96.2,111.3,117.6,122.3,122.5,128.5,128.8,129.7,131.6,131.7$, 
138.9, 153.6. IR: $3042,1742,1580,1520,1491,1454,1306,1281,1239,1214,1103,1063,1039,953$ $\mathrm{cm}^{-1}$. HRMS (EI) calc. for $\mathrm{C}_{16} \mathrm{H}_{13} \mathrm{NO}_{2} 251.0950$, found 251.0946.

\section{Characterization of 4}<smiles>CC(=O)n1c(-c2ccccc2)cc2ccccc21</smiles>

Methyl 2-phenyl-1H-indole-1-carboxylate (4). Yellow oil. ${ }^{1} \mathrm{H} \mathrm{NMR}\left(\mathrm{CDCl}_{3}, 500 \mathrm{MHz}\right): \delta 3.82$ (s, $3 \mathrm{H}), 6.63(\mathrm{~s}, 1 \mathrm{H}), 7.29$ (t, 1H, $J=7.5 \mathrm{~Hz}), 7.35-7.46(\mathrm{~m}, 6 \mathrm{H}), 7.58(\mathrm{~d}, 1 \mathrm{H}, J=7.5 \mathrm{~Hz}), 8.18(\mathrm{~d}, 1 \mathrm{H}, J=$ $8.5 \mathrm{~Hz}) .{ }^{13} \mathrm{C} \mathrm{NMR}\left(\mathrm{CDCl}_{3}, 125 \mathrm{MHz}\right): \delta 53.4,110.8,115.4,120.6,123.3,124.5,127.7,127.8,128.6$, 129.4, 134.1, 137.1, 140.5, 152.2. IR: 1740, 1454, 1439, 1361, 1329, 1266, 1220, 1131, $1050 \mathrm{~cm}^{-1}$. HRMS (EI) calc. for $\mathrm{C}_{16} \mathrm{H}_{13} \mathrm{NO}_{2} 251.0948$, found 251.0946 .

\section{Preparation of 5}<smiles>CC(C)COC(=O)c1ccccc1C#Cc1ccccc1</smiles>

tert-Butyl 2-(phenylethynyl)benzoate (5) was prepared according to the published procedure. Spectral data were consistent with the values previously reported. ${ }^{20}{ }^{1} \mathrm{H}$ NMR $\left(\mathrm{CDCl}_{3}, 500 \mathrm{MHz}\right): \delta 1.62$ (s, 9H), 7.34-7.39 (m, 4H), $7.45(\mathrm{td}, 1 \mathrm{H}, J=1.6$ and $7.7 \mathrm{~Hz}), 7.55-7.59(\mathrm{~m}, 2 \mathrm{H}), 7.62(\mathrm{dd}, 1 \mathrm{H}, J=1.1$ and $7.7 \mathrm{~Hz}), 7.88(\mathrm{dd}, 1 \mathrm{H}, 1.2$ and $7.8 \mathrm{~Hz})$.

\section{Characterization of 6}<smiles>O=c1oc(-c2ccccc2)cc2ccccc12</smiles>

3-Phenyl-1H-isochromen-1-one (6) was identified by comparison to published characterization data. Spectral data were consistent with the values previously reported. ${ }^{21}{ }^{1} \mathrm{H}$ NMR $\left(\mathrm{CDCl}_{3}, 500 \mathrm{MHz}\right): \delta 6.98$ (s, 1H), 7.43-7.54 (m, 5H), 7.74 (t, 1H, J=7.5 Hz), 7.90 (d, 2H, J=7.3 Hz), 8.33 (d, 1H, J=8.2 Hz). 


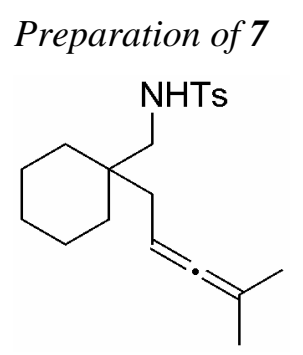

4-Methyl- $N$-((1-(4-methylpenta-2,3-dienyl)cyclohexyl)methyl)benzenesulfonamide (7) was preprared according to the published procedure. Spectral data were consistent with the values previously reported. ${ }^{22}$ ${ }^{1} \mathrm{H}$ NMR (toluene- $\left.\mathrm{d}_{8}, 500 \mathrm{MHz}\right): \delta 1.1-1.42(\mathrm{~m}, 10 \mathrm{H}), 1.61(\mathrm{~s}, 3 \mathrm{H}), 1.62(\mathrm{~s}, 3 \mathrm{H}), 1.87(\mathrm{~d}, 2 \mathrm{H}, J=8.0 \mathrm{~Hz})$, 1.95 (s, 3H), 2.80 (d, 2H), 7.0 Hz), 4.82-4.88 (m, 2H), 6.82 (d, 2H, J=8.0 Hz), 7.81 (d, 2H, J = 8.0 Hz).

\section{Characterization of $\boldsymbol{8}$}

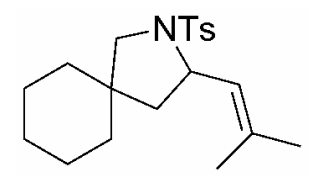

3-(2-Methylprop-1-enyl)-2-tosyl-2-azaspiro[4.5]decane (8) was identified by comparison to published characterization data. Spectral data were consistent with the values previously reported. ${ }^{23}{ }^{1} \mathrm{H}$ NMR (toluene- $\left.\mathrm{d}_{8}, 500 \mathrm{MHz}\right): \delta$ 0.8-1.4 (m, 12H), $1.60(\mathrm{~s}, 3 \mathrm{H}), 1.69(\mathrm{~s}, 3 \mathrm{H}), 1.98(\mathrm{~s}, 3 \mathrm{H}), 3.00(\mathrm{~d}, 1 \mathrm{H}, J=10.0$ $\mathrm{Hz}), 3.47$ (d, 1H, $J=10.4 \mathrm{~Hz}), 4.41$ (q, 1H, $J=8.8 \mathrm{~Hz}), 6.86$ (d, 2H, $J=8.0 \mathrm{~Hz}), 7.77$ (d, 2H, $J=8.0 \mathrm{~Hz})$.

\section{Preparation of 9}

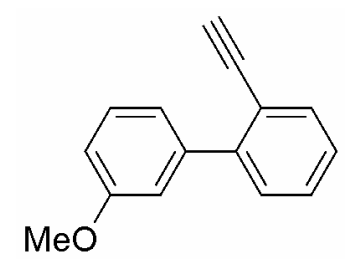

2-Ethynyl-3'-methoxybiphenyl (9) was prepared according to the published procedure. Spectral data were consistent with the values previously reported. ${ }^{24}{ }^{1} \mathrm{H}$ NMR $\left(\mathrm{CDCl}_{3}, 600 \mathrm{MHz}\right): \delta 3.07(\mathrm{~s}, 1 \mathrm{H}), 3.87$ (s, 3H), 6.93 (ddd, 1H, $J=0.6,2.4$ and $8.4 \mathrm{~Hz}), 7.17(\mathrm{~m}, 2 \mathrm{H}), 7.31(\mathrm{td}, 1 \mathrm{H}, J=2.4$ and $7.2 \mathrm{~Hz}), 7.35$ (t, $1 \mathrm{H}, J=8.0 \mathrm{~Hz}), 7.41(\mathrm{~m}, 2 \mathrm{H}), 7.63(\mathrm{~d}, 1 \mathrm{H}, J=8.4 \mathrm{~Hz})$. 


\section{Characterization of $\mathbf{1 0}$}
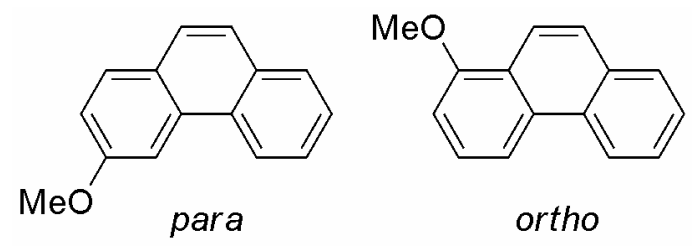

3-Methoxyphenanthrene (10) was identified by comparison to published characterization data. Spectral data were consistent with the values previously reported. ${ }^{24}$ (para-10): ${ }^{1} \mathrm{H} \mathrm{NMR}\left(\mathrm{CDCl}_{3}, 600\right.$ MHz): $\delta 4.04(\mathrm{~s}, 3 \mathrm{H}), 7.26(\mathrm{dd}, 1 \mathrm{H}, J=2.0$ and $8.5 \mathrm{~Hz}), 7.53-7.67(\mathrm{~m}, 3 \mathrm{H}), 7.69(\mathrm{~d}, 1 \mathrm{H}, J=9.0 \mathrm{~Hz}), 7.82$ (d, 1H, $J=9.0 \mathrm{~Hz}$ ), 7.89 (d, 1H, $J=7.2 \mathrm{~Hz}), 8.07$ (d, 1H, $J=2.4 \mathrm{~Hz}$ ), 8.62 (d, 1H, $J=8.4 \mathrm{~Hz}$ ). (ortho10): ${ }^{1} \mathrm{H}$ NMR $\left(\mathrm{CDCl}_{3}, 600 \mathrm{MHz}\right): \delta 4.05$ (s, 3H), 7.02 (d, $\left.1 \mathrm{H}, J=7.8 \mathrm{~Hz}\right), 7.58-7.66(\mathrm{~m}, 3 \mathrm{H}), 7.75(\mathrm{~d}, 1 \mathrm{H}$, $J=9.0 \mathrm{~Hz}), 7.91(\mathrm{~d}, 1 \mathrm{H}, J=9.0 \mathrm{~Hz}), 8.25(\mathrm{~d}, 1 \mathrm{H}, J=9.0 \mathrm{~Hz}), 8.29(\mathrm{~d}, 1 \mathrm{H}, J=8.4 \mathrm{~Hz}), 8.68(\mathrm{~d}, 1 \mathrm{H}, J=$ $8.4 \mathrm{~Hz})$.

\section{Preparation of 11}

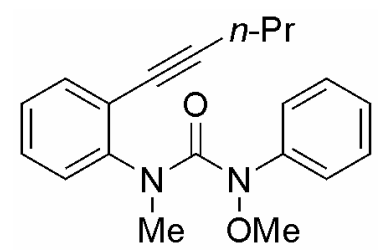

$N$-Methoxy- $N$ '-methyl- $N$ '-(2-pent-1-ynyl)phenyl)- $N$-phenylurea (11) was prepared according the published procedure. Spectral data were consistent with the values previously reported. ${ }^{25}{ }^{1} \mathrm{H}$ NMR $\left(\mathrm{CDCl}_{3}, 500 \mathrm{MHz}\right): \delta 1.05$ (t, 3H, $\left.J=7.5 \mathrm{~Hz}\right), 1.62$ (q, 2H, $\left.J=7.3 \mathrm{~Hz}\right), 3.21(\mathrm{~s}, 3 \mathrm{H}), 3.28$ (s, 3H), 7.05 (dd, $1 \mathrm{H}, J=1.1$ and $7.9 \mathrm{~Hz}), 7.14(\mathrm{t}, 2 \mathrm{H}, J=7.8 \mathrm{~Hz}), 7.19$ (d, 3H, $J=8.2 \mathrm{~Hz}), 7.26(\mathrm{t}, 2 \mathrm{H}, J=7.2 \mathrm{~Hz}$ ), $7.38(\mathrm{dd}, 1 \mathrm{H}, J=1.6$ and $7.6 \mathrm{~Hz})$.

\section{Characterization of 12}<smiles>CCCCc1c(Cc2c(C(C)C)n(C)c3ccccc23)c2ccccc2n1C</smiles>

Bis(1-methyl-2-propyl-1H-indol-3-yl)methane (12). Orange oil. ${ }^{1} \mathrm{H}$ NMR $\left(\mathrm{CDCl}_{3}, 600 \mathrm{MHz}\right): \delta 0.86$ (t, 6H, $J=7.2 \mathrm{~Hz}), 1.47(\mathrm{p}, 4 \mathrm{H}, J=7.6 \mathrm{~Hz}), 2.70(\mathrm{t}, 4 \mathrm{H}, J=7.8 \mathrm{~Hz}), 3.65(\mathrm{~s}, 6 \mathrm{H}), 4.17(\mathrm{~s}, 2 \mathrm{H})$, $6.96(\mathrm{t}, 2 \mathrm{H}, J=7.2 \mathrm{~Hz}), 7.10(\mathrm{t}, 2 \mathrm{H}, J=7.2 \mathrm{~Hz}), 7.22(\mathrm{~d}, 2 \mathrm{H}, J=7.8 \mathrm{~Hz}), 7.40(\mathrm{~d}, 2 \mathrm{H}$, 
$J=7.8 \mathrm{~Hz}) .{ }^{13} \mathrm{C} \mathrm{NMR}\left(\mathrm{CDCl}_{3}, 150 \mathrm{MHz}\right): \delta 13.9\left(\mathrm{CH}_{3}\right), 19.8\left(\mathrm{CH}_{2}\right), 23.1\left(\mathrm{CH}_{2}\right), 26.7\left(\mathrm{CH}_{2}\right), 29.5$ $\left(\mathrm{CH}_{3}\right), 108.4(\mathrm{CH})$, 110.4, (C-q), $118.5(\mathrm{CH}), 118.6(\mathrm{CH}), 120.2(\mathrm{CH}), 128.2(\mathrm{C}-\mathrm{q}), 136.6(\mathrm{C}-\mathrm{q}), 137.2$ (C-q). LRMS (EI): $m / z=358.20$. HSQC correlations $\left(\mathrm{CDCl}_{3}, 600\right.$ and $\left.150 \mathrm{MHz}\right):{ }^{1} \mathrm{H} 0.86$ and ${ }^{13} \mathrm{C} 13.9$, ${ }^{1} \mathrm{H} 1.47$ and ${ }^{13} \mathrm{C} 23.1,{ }^{1} \mathrm{H} 2.70$ and ${ }^{13} \mathrm{C} 26.7,{ }^{1} \mathrm{H} 3.65$ and ${ }^{13} \mathrm{C} 29.5,{ }^{1} \mathrm{H} 4.17$ and ${ }^{13} \mathrm{C} 19.8,{ }^{1} \mathrm{H} 6.96 ; 7.40$ and ${ }^{13} \mathrm{C} 118.5 ; 118.6,{ }^{1} \mathrm{H} 7.10$ and ${ }^{13} \mathrm{C} 120.2,{ }^{1} \mathrm{H} 7.22$ and ${ }^{13} \mathrm{C} 108.4$.

\section{Characterization of $\mathbf{1 3}$}

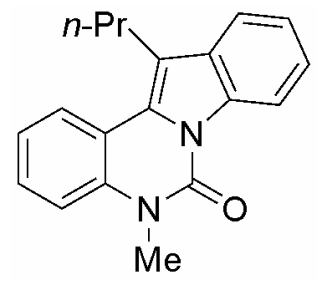

5-Methyl-12-propylindolo[1,2-c]quinazolin-6(5H)-one (13) was identified by comparison to published characterization data. Spectral data were consistent with the values previously reported. ${ }^{25} \quad{ }^{1} \mathrm{H}$ NMR $\left(\mathrm{CDCl}_{3}, 500 \mathrm{MHz}\right): \delta 1.11(\mathrm{t}, 3 \mathrm{H}, J=7.2 \mathrm{~Hz}), 1.82($ sextet, $2 \mathrm{H}, J=7.5 \mathrm{~Hz}), 3.16(\mathrm{t}, 2 \mathrm{H}$, $J=7.8 \mathrm{~Hz}), 3.72(\mathrm{~s}, 3 \mathrm{H}), 7.25-7.32(\mathrm{~m}, 2 \mathrm{H}), 7.38-7.45(\mathrm{~m}, 3 \mathrm{H}), 7.69-7.71(\mathrm{~m}, 1 \mathrm{H}), 8.09$ (dd, 1H, $J=8.4 \mathrm{~Hz}$ and $1.2 \mathrm{~Hz}), 8.73-8.75(\mathrm{~m}, 1 \mathrm{H})$.

\section{Representative Procedure for Catalytic Reactions}

To a dry $10 \mathrm{~mL}$ glass reaction tube with stirbar and Teflon screwvalve cap under Ar was added 2-(phenylethynyl)phenol (1) (20 mg, $0.1025 \mathrm{mmol}), \operatorname{Pt}(2.9 \mathrm{~nm}) / \mathrm{PVP} / \mathrm{SBA}-15$ (50 mg, $0.0026 \mathrm{mmol}, 2.5$ mol\%), $\mathrm{PhICl}_{2}(2.1 \mathrm{mg}, 0.0077 \mathrm{mmol}, 7.5 \mathrm{~mol} \%)$, mesitylene (15 $\mu \mathrm{L}$, internal standard, Aldrich) and toluene- $\mathrm{d}_{8}(2 \mathrm{~mL}$, Cambridge Isotopes). The reaction mixture was degassed (freeze/pump method) three times and placed under $1 \mathrm{~atm}$ of Ar. The reaction tube was sealed and the mixture heated with stirring to $100^{\circ} \mathrm{C}$ for 15 hours. The mixture was then cooled to $\mathrm{rt}$ and the solid catalyst filtered by glass microfiber filter. The filtrate was transferred to a NMR tube for analysis.

For the $\mathrm{Pt}_{40} / \mathrm{G} 4 \mathrm{OH} / \mathrm{SBA}-15$ catalyst, prior to addition of all other reaction materials, the catalyst was added to the dry $10 \mathrm{~mL}$ glass reaction tube and placed under $1 \mathrm{~atm}$ of $\mathrm{H}_{2}$. The catalyst was then heated to $100^{\circ} \mathrm{C}$ for 24 hours. After cooling to $\mathrm{rt}$ and replacing the $\mathrm{H}_{2}$ atmosphere with Ar, the reaction setup was continued as discussed above.

2-Phenylbenzofuran (2) can be isolated in the following manner. The toluene solution containing the product from the catalytic reaction was concentrated and purified by flash chromatography (5\% ethyl acetate/hexanes, Fisher ACS grade). 


\section{Preparation of Wang Resin-Bound Benzoate 14.}

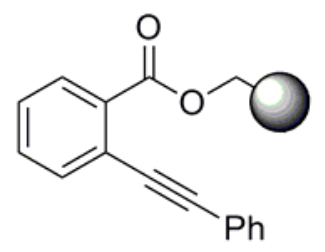

To a $30 \mathrm{~mL}$ polypropylene Spe-ed cartridge with $70 \mu \mathrm{PE}$ frit was added Wang resin $(1.25 \mathrm{~g}, 1.13$ mmol, NovaBioChem). $\mathrm{CH}_{2} \mathrm{Cl}_{2}(15 \mathrm{~mL}$, Fisher HPLC grade) was then added and the resin swelled for 30 min. Then, 2-(phenylethynyl)benzoic $\operatorname{acid}^{26}(1.25 \mathrm{~g}, 5.63 \mathrm{mmol})$, diisopropylcarbodiimide $(0.876 \mathrm{~mL}$, $5.63 \mathrm{mmol})$ and dimethylaminopyridine $(137 \mathrm{mg}, 1.13 \mathrm{mmol})$ was added. The cartridge was capped and shaken for $100 \mathrm{~h}$. The $\mathrm{CH}_{2} \mathrm{Cl}_{2}$ was then removed, and the resin washed with dimethylformamide $(3 \times 10$ mL, Fisher), tetrahydrofuran ( $3 \times 10 \mathrm{~mL}$, Fisher ACS grade), methanol ( $3 \times 10 \mathrm{~mL}$, Fisher ACS grade), tetrahydrofuran $\left(3 \times 10 \mathrm{~mL}\right.$, Fisher ACS grade) and then $\mathrm{CH}_{2} \mathrm{Cl}_{2}(3 \times 10 \mathrm{~mL}$, Fisher HPLC grade). The mixture was allowed to sit for 2 minutes after each addition of solvent before the solvent was removed. The resin was then dried in vacuo for $24 \mathrm{~h}$ at $\mathrm{rt}$. The Wang resin-bound 2-(phenylethynyl)benzoate (14) was transferred to a polypropylene bottle and stored at $-20^{\circ} \mathrm{C}$ when not in use.

To determine the percent loading of substrate on the resin, the following procedure was employed. A solution of $\mathrm{CH}_{2} \mathrm{Cl}_{2}$ (9 mL, Fisher HPLC grade), trifluoroacetic acid (0.95 mL, Aldrich), $\mathrm{H}_{2} \mathrm{O}(0.025 \mathrm{~mL}$, deionized), and triisopropylsilane $(0.025 \mathrm{~mL}$, Aldrich). To a $6 \mathrm{~mL}$ polypropylene Spe-ed cartridge with $70 \mu \mathrm{PE}$ frit was added Wang resin-bound 2-(phenylethynyl)benzoate (14) $(300 \mathrm{mg})$ and $5 \mathrm{~mL}$ of the previously described solution. The cartridge was capped and shaken for $2 \mathrm{~h}$. The solution was then collected and the resin washed with an additional $5 \mathrm{~mL}$ of the previously described solution. The resin was further washed with $\mathrm{CH}_{2} \mathrm{Cl}_{2}(3 \times 5 \mathrm{~mL}$, Fisher HPLC grade). All wash solutions were collected and combined with the first solution and concentrated. The residue was purified by flash chromatography (30\%-50\% ethyl acetate/hexanes (Fisher HPLC grade)) to yield $26 \mathrm{mg}$ of 2-(phenylethynyl)benzoic acid. This correlates to a loading of $43 \%$ on the resin.

\section{Representative Procedure for 3-Phase Test}

To a dry $10 \mathrm{~mL}$ glass reaction tube with stirbar and Teflon screwvalve cap under Ar was added Wang resin-bound 2-(phenylethynyl)benzoate (14) $(20 \mathrm{mg}, 0.1025 \mathrm{mmol}), \mathrm{Pt}(2.9 \mathrm{~nm}) / \mathrm{PVP} / \mathrm{SBA}-15$ (50 mg, $0.0026 \mathrm{mmol}, 2.5 \mathrm{~mol} \%), \mathrm{PhICl}_{2}(2.1 \mathrm{mg}, 0.0077 \mathrm{mmol}, 7.5 \mathrm{~mol} \%)$, mesitylene (15 $\mu \mathrm{L}$, internal standard, Aldrich) and toluene- $\mathrm{d}_{8}(2 \mathrm{~mL}$, Cambridge Isotopes). The reaction tube was sealed and the mixture heated with stirring to $100^{\circ} \mathrm{C}$ for 15 hours. The mixture was then cooled to $\mathrm{rt}$ and the solid catalyst and resin-bound starting material filtered by glass microfiber filter. The filtrate was transferred to a NMR tube for analysis. 
For the $\mathrm{Pt}_{40} / \mathrm{G} 4 \mathrm{OH} / \mathrm{SBA}-15$ catalyst, prior to addition of all other reaction materials, the catalyst was added to a dry $10 \mathrm{~mL}$ glass reaction tube and placed under $1 \mathrm{~atm}$ of $\mathrm{H}_{2}$. The catalyst was then heated to $100^{\circ} \mathrm{C}$ for 24 hours. After cooling to rt, the reaction setup was continued as discussed above.

\section{Procedure for Reaction with NP Pellet}

The $\mathrm{Pt}_{40} / \mathrm{G} 4 \mathrm{OH} / \mathrm{mesoporous} \mathrm{silica} \mathrm{pellet} \mathrm{catalyst} \mathrm{(190} \mathrm{mg,} 0.007 \mathrm{mmol}, 6 \mathrm{~mol} \%, 0.7 \mathrm{wt} \%$ ) was added to a dry $10 \mathrm{~mL}$ glass Schlenck reaction tube with stirbar and placed under $1 \mathrm{~atm}$ of $\mathrm{H}_{2}$. The catalyst was then heated to $100^{\circ} \mathrm{C}$ for 24 hours. After cooling to rt, the catalyst was placed under vacuum followed by Ar. Then, 2-(phenylethynyl)phenol (1) $(21.9 \mathrm{mg}, 0.113 \mathrm{mmol})$, hexamethylbenzene (18 $\mathrm{mg}$, internal standard, Aldrich), $3.5 \mathrm{~mL}$ of toluene (HPLC, Fisher) and $\mathrm{PhICl}_{2}$ (5.6 mg, $0.020 \mathrm{mmol}, 12 \mathrm{~mol} \%$ ) was added. The catalyst mixture was degassed (freeze/pump method) three times and placed under $1 \mathrm{~atm}$ of Ar. The reaction was then heated with stirring to $100^{\circ} \mathrm{C}$. The mixture was monitored by removal of aliquots via syringe, dilution and submission to GC-MS. After $42 \%$ yield was obtained, the solution was transferred via cannula to a second dry $10 \mathrm{~mL}$ glass Schlenck reaction tube with stirbar under a positive pressure of $\mathrm{Ar}$ at $100^{\circ} \mathrm{C}$. Then, a fresh, degassed (freeze/pump method) solution of 2-(phenylethynyl)phenol (1) (21.9 mg, $0.0897 \mathrm{mmol})$, hexamethylbenzene (18 $\mathrm{mg}$, internal standard, Aldrich) and $3.5 \mathrm{~mL}$ of toluene (HPLC, Fisher) was added via cannula to the original $10 \mathrm{~mL}$ glass Schlenck reaction tube under $\mathrm{Ar}$ at $100^{\circ} \mathrm{C}$. The solution was then stirred under Ar at $100^{\circ} \mathrm{C}$. Both reaction tubes now containing solution were monitored by removal of aliquots via syringe, dilution and submission to GC-MS.

\section{Recycling Data}

After isolation by filtration of the supported NP catalyst, the catalyst was washed with $\mathrm{CH}_{2} \mathrm{Cl}_{2}(2 \times 1$ $\mathrm{mL}$ ) and dried in vacuo. The catalyst was then added to a dry $10 \mathrm{~mL}$ glass reaction tube with stirbar and Teflon screwvalve cap and reduced under $1 \mathrm{~atm}$ of $\mathrm{H}_{2}$ at $100^{\circ} \mathrm{C}$ for 24 hours. The catalytic reaction was then carried out as described above.

Recycling results (with retreatment):

Initial: $96 \%$ conversion, $92 \%$ yield

$1 \mathrm{x}:>99 \%$ conversion, $96 \%$ yield

$2 \mathrm{x}$ : $>99 \%$ conversion, $98 \%$ yield

$3 \mathrm{x}:>99 \%$ conversion, $98 \%$ yield

$4 \mathrm{x}$ : $>99 \%$ conversion, $97 \%$ yield

For recycling without retreatment, after reaction at $100^{\circ} \mathrm{C}$, the mixture was cooled to $\mathrm{rt}$ and centrifuged (3 min, $8000 \mathrm{rpm})$. The supernatant was removed and toluene $(1.0 \mathrm{~mL})$ was added. 
Sonication was then used to redisperse the solid catalyst in toluene. The catalyst suspension was then added to a solution of starting material, mesitylene and toluene $(1.0 \mathrm{~mL})$ in a dry $10 \mathrm{~mL}$ glass reaction tube with stirbar and Teflon screwvalve cap under Ar. The reaction mixture was degassed (freeze/pump method) three times and placed under 1 atm of Ar. The catalytic reaction was then carried out as described above.

\section{XPS Data}

NPs were deposited onto a silicon wafer. Experiments were performed on a Perkin-Elmer PHI 5300 XPS spectrometer with a positron-sensitive detector and a hemispherical energy analyzer in an ionpumped chamber (evacuated to $2 \times 10^{-9}$ Torr). The $\mathrm{Al} \mathrm{K} \mathrm{K}_{\alpha}(B E=1486.6 \mathrm{eV}) \mathrm{X}$-ray source of the XPS spectrometer was operated at $300 \mathrm{~W}$ with $15 \mathrm{kV}$ acceleration voltage.

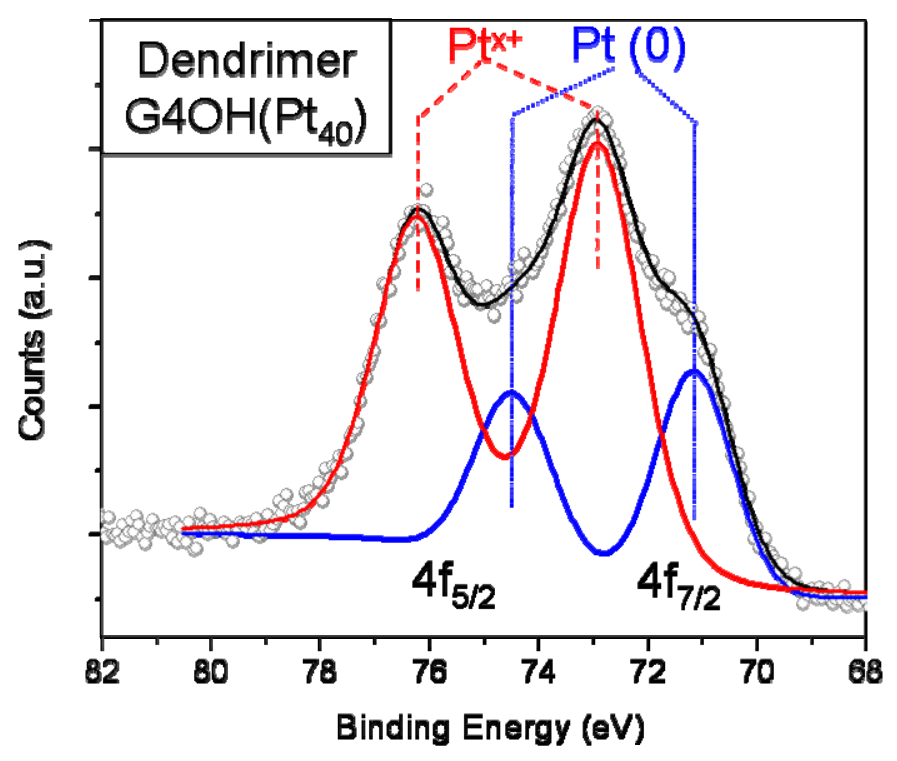

Figure S2. X-ray Photoelectron Spectra for $\mathrm{Pt}_{40} / \mathrm{G} 4 \mathrm{OH}$. 


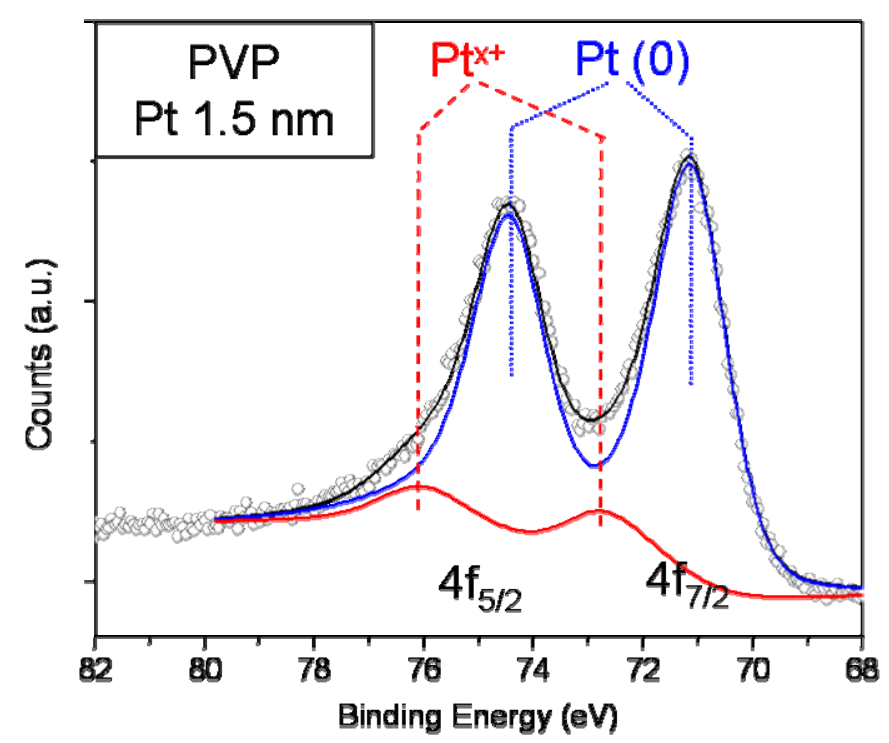

Figure S3. X-ray Photoelectron Spectra for Pt (1.5 nm)/PVP.

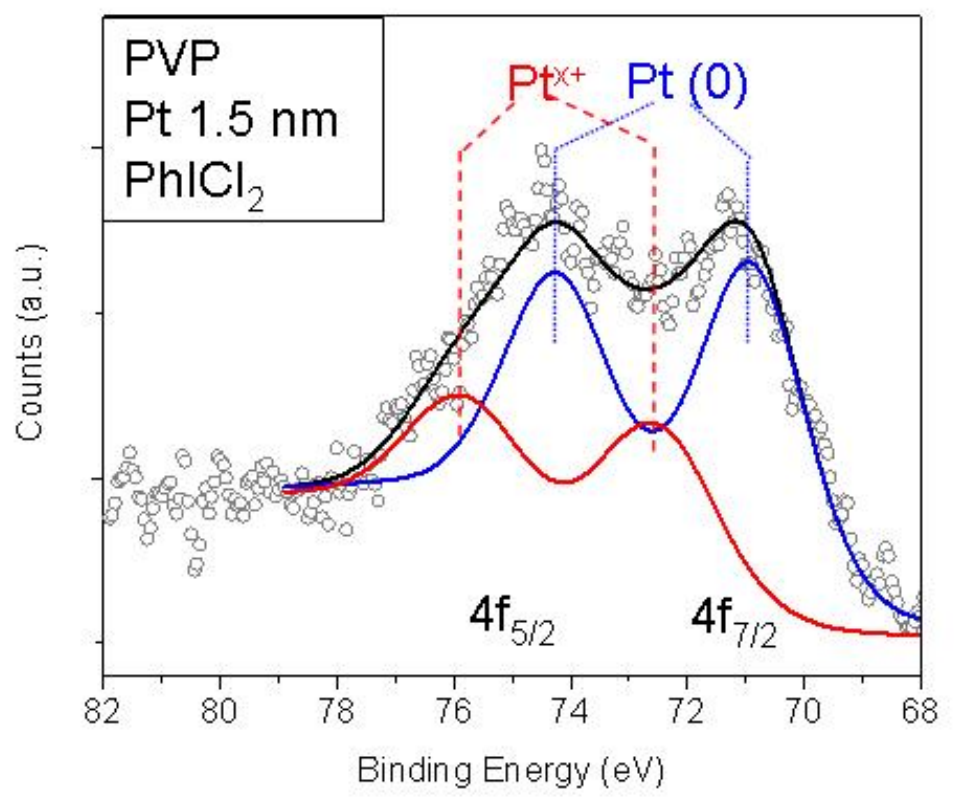

Figure S4. X-ray Photoelectron Spectra for Pt $(1.5 \mathrm{~nm}) / \mathrm{PVP} / \mathrm{SBA}-15(4 \mathrm{wt} \%)$ NPs after treatment with $\mathrm{PhICl}_{2}$.

Treatment conditions: To a dry $10 \mathrm{~mL}$ glass reaction tube with stirbar and Teflon screwvalve cap under Ar was added Pt(1.5 nm)/PVP/SBA-15 (4 wt\%) (50 mg, $0.0103 \mathrm{mmol}), \mathrm{PhICl}_{2}(8.5 \mathrm{mg}, 0.0307$ 
mmol), mesitylene (15 $\mu \mathrm{L}$, internal standard, Aldrich) and toluene (2 mL, Fisher HPLC grade). The reaction mixture was degassed (freeze/pump method) three times and placed under 1 atm of Ar. The reaction tube was sealed and the mixture heated with stirring to $100^{\circ} \mathrm{C}$ for 15 hours. After cooling to rt a sample was deposited on a silicon wafer and quickly transferred to the XPS vacuum chamber.

\section{Monitoring of Reaction Yield vs Time for Cyclization of 1 to 2}

Reactions were conducted at a larger scale but as described above, except with hexamethylbenzene as internal standard. Aliquots of reaction were filtered by glass microfiber filter, diluted with ethyl acetate (Fisher HPLC grade) and analyzed by GC-MS. All catalysts treated in situ with $\mathrm{PhICl}_{2}$ (3 cat. equiv.) unless otherwise stated.
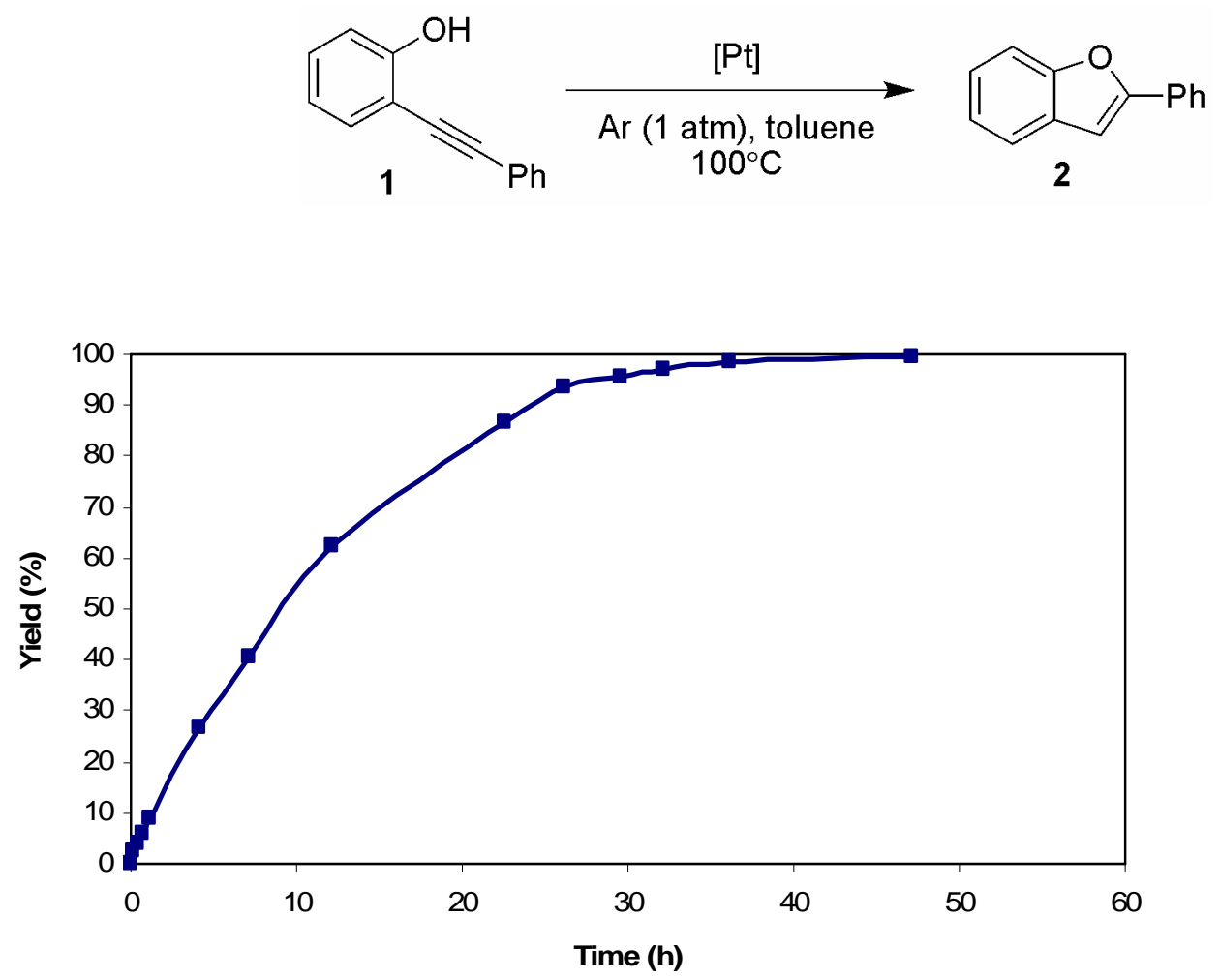

Figure $\mathrm{S} 5 . \mathrm{Pt}_{40} / \mathrm{G} 4 \mathrm{OH} / \mathrm{SBA}-15$ (3 mol\%). Initial use of catalyst. 


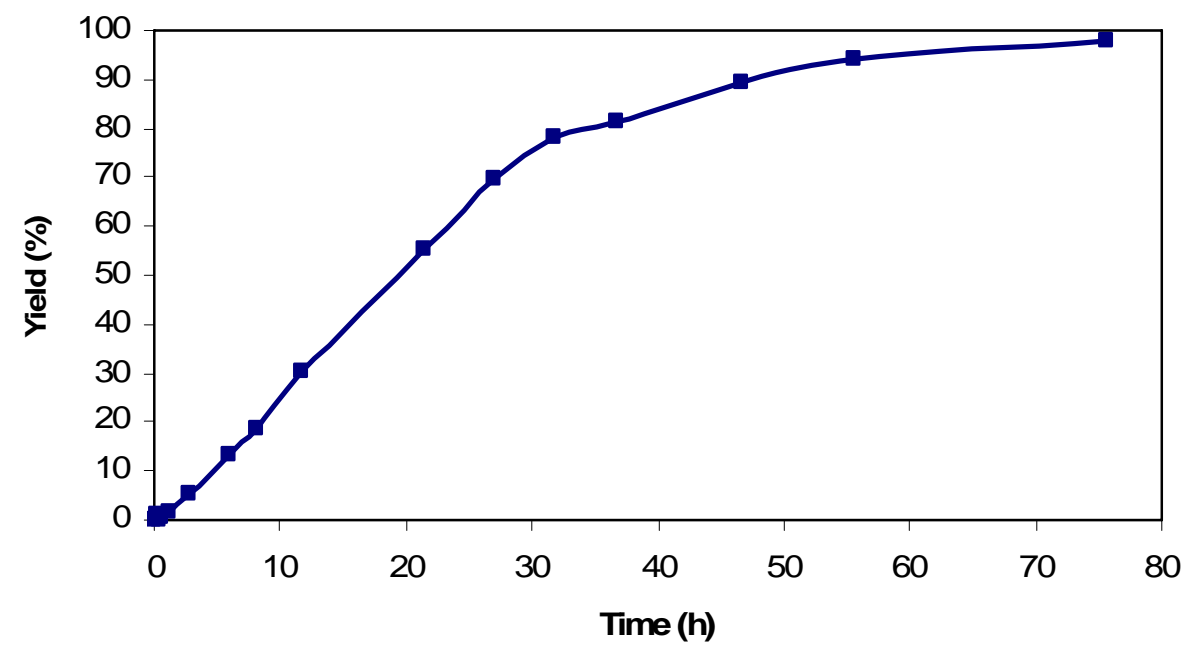

Figure S6. $\mathrm{Pt}_{40} / \mathrm{G} 4 \mathrm{OH} / \mathrm{SBA}-15$ (3 mol\%). Recycle of catalyst without reduction/retreatment.

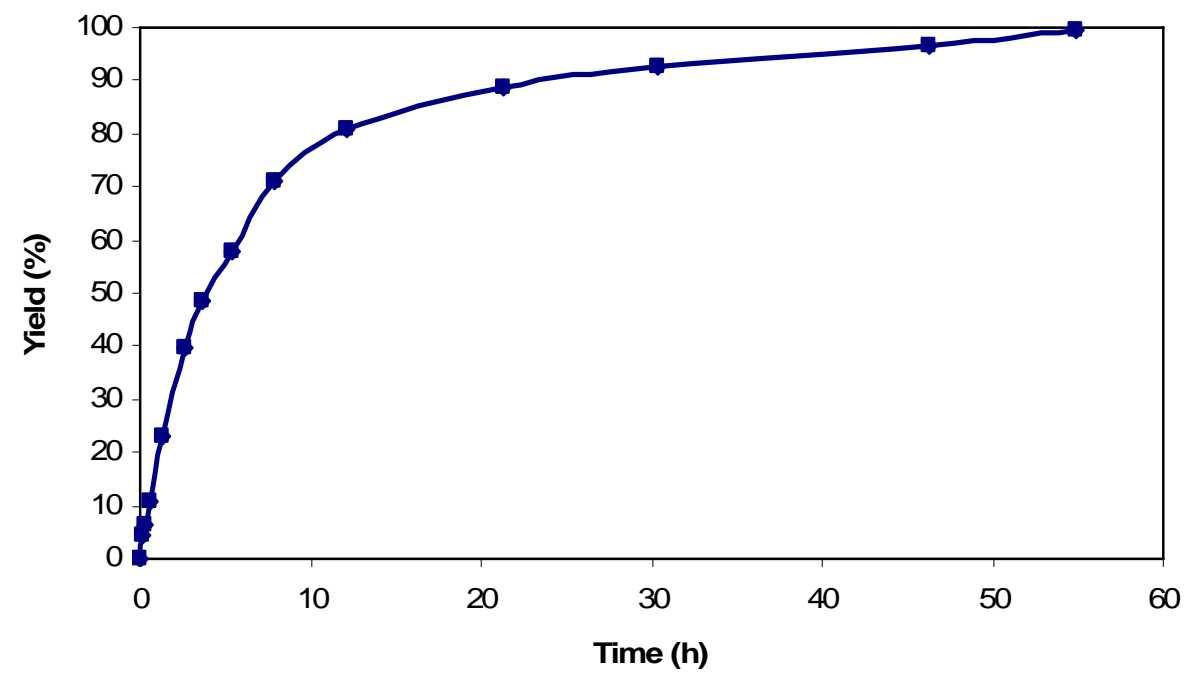

Figure S7. $\mathrm{Pt}_{40} / \mathrm{G} 4 \mathrm{OH} / \mathrm{SBA}-15$ (3 mol\%). Recycle of catalyst with reduction/retreatment. 


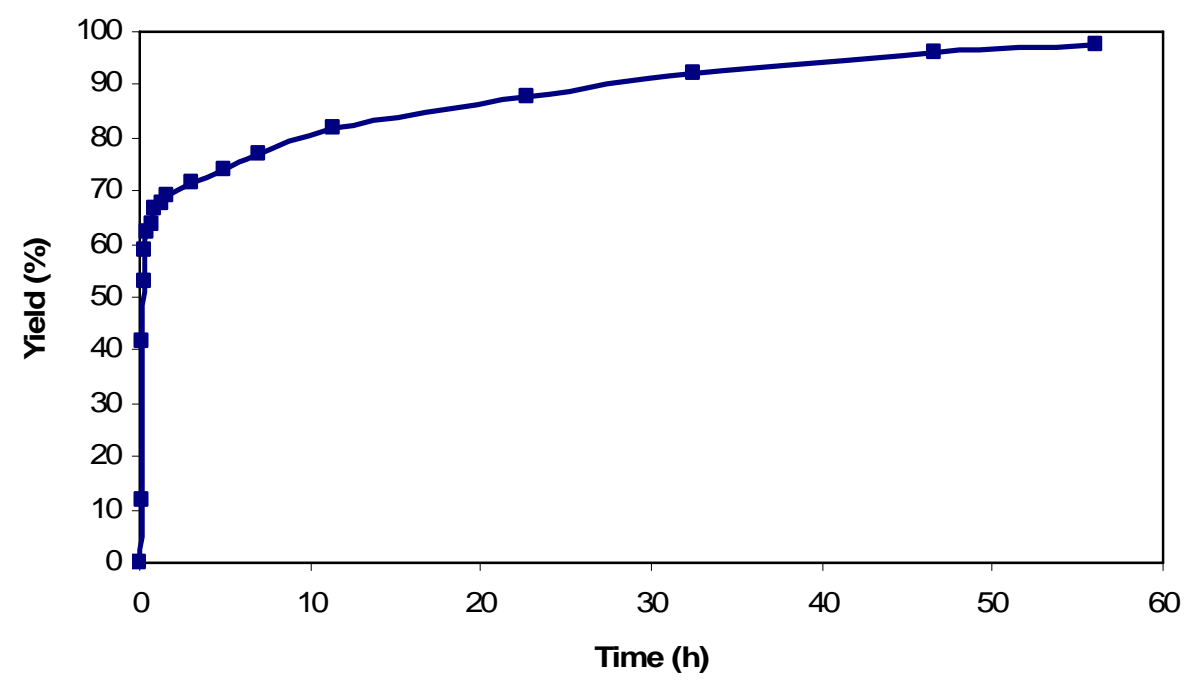

Figure S8. Pt (1.5 nm)/PVP/SBA-15 (1 mol\%). Initial use of catalyst.

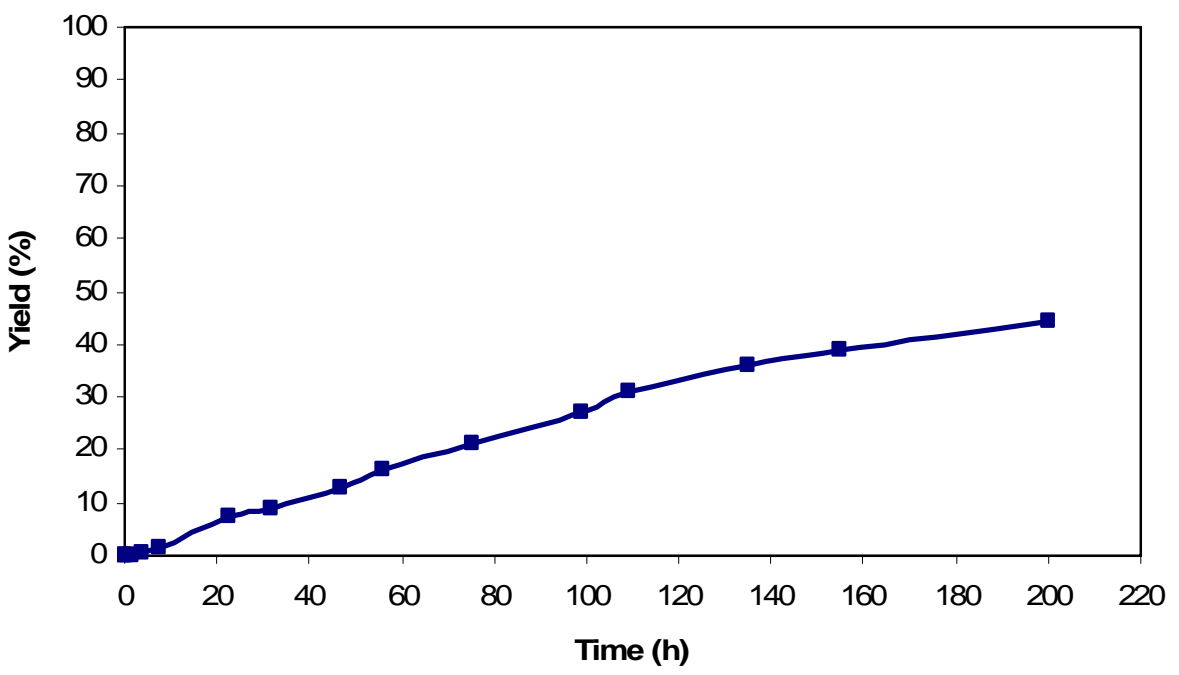

Figure S9. Pt (1.5 nm)/PVP/SBA-15 (1 mol\%). Recycle of catalyst without reduction/retreatment. 


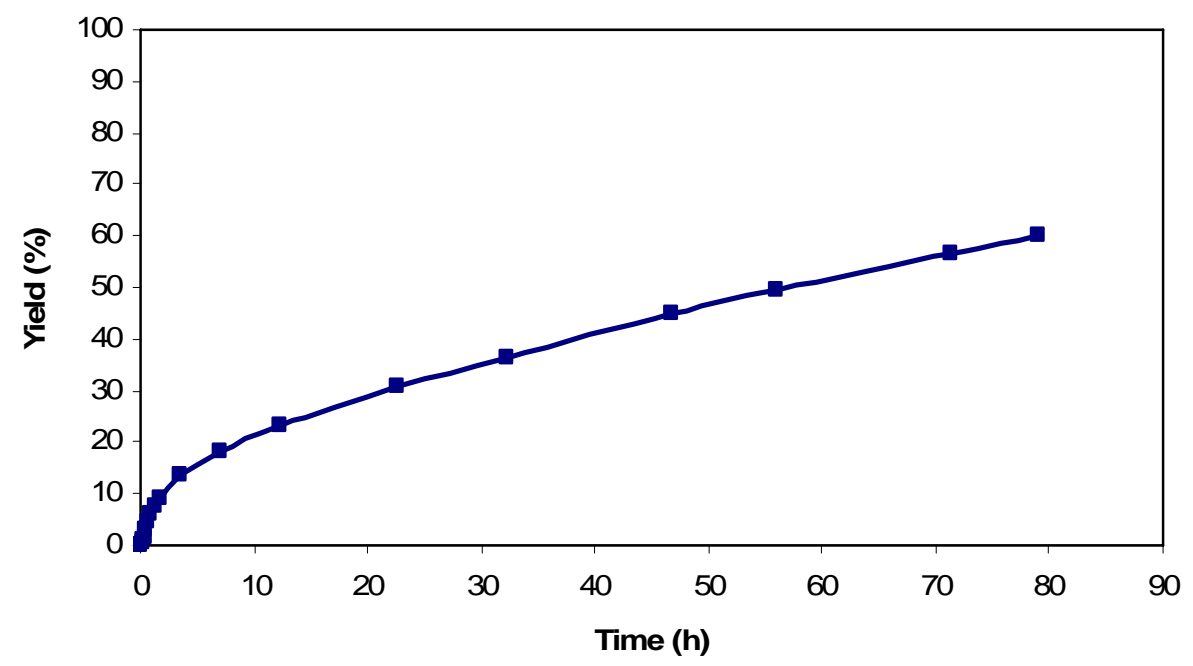

Figure S10. Pt (1.5 nm)/PVP/SBA-15 (1 mol\%). Recycle of catalyst with reduction/retreatment.

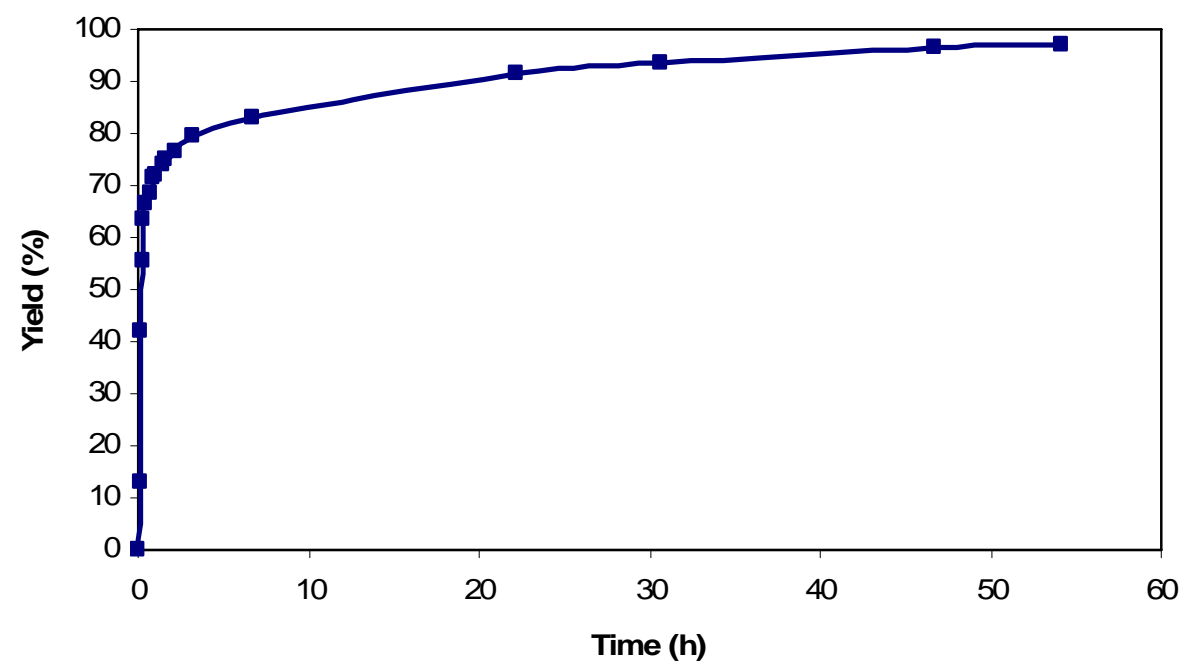

Figure S11. Pt (2.9 nm)/PVP/SBA-15 (1 mol\%). Initial use of catalyst. 


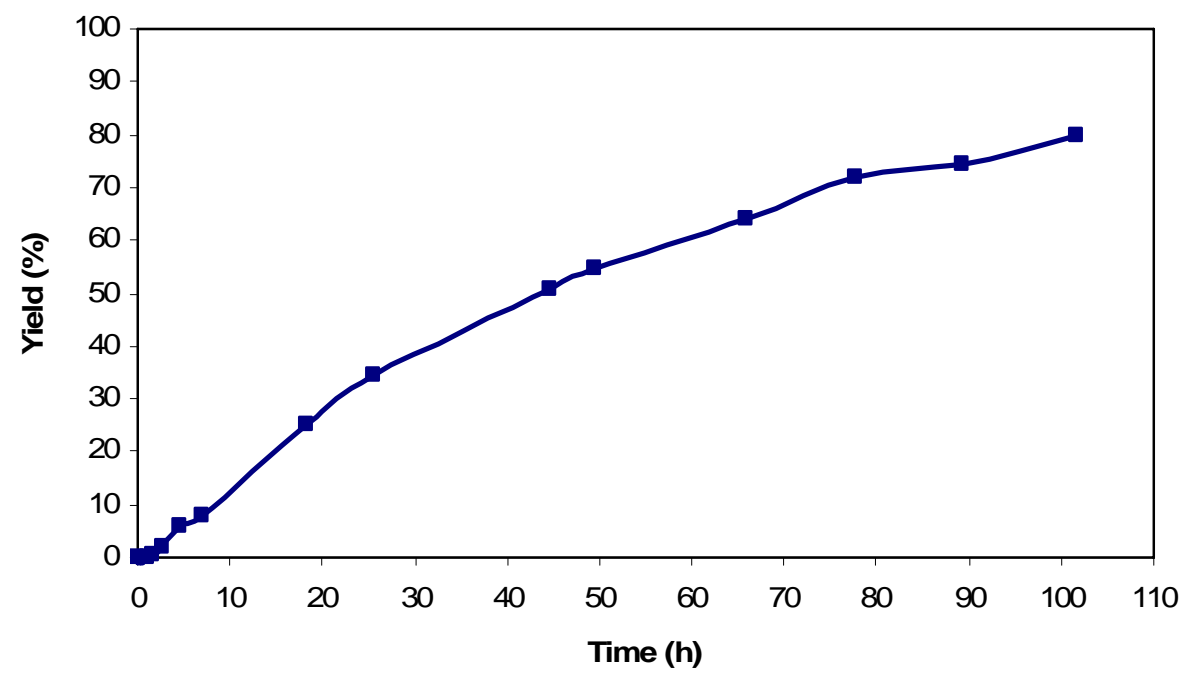

Figure S12. Pt (2.9 nm)/PVP/SBA-15 (1 mol\%). Recycle of catalyst without reduction/retreatment.

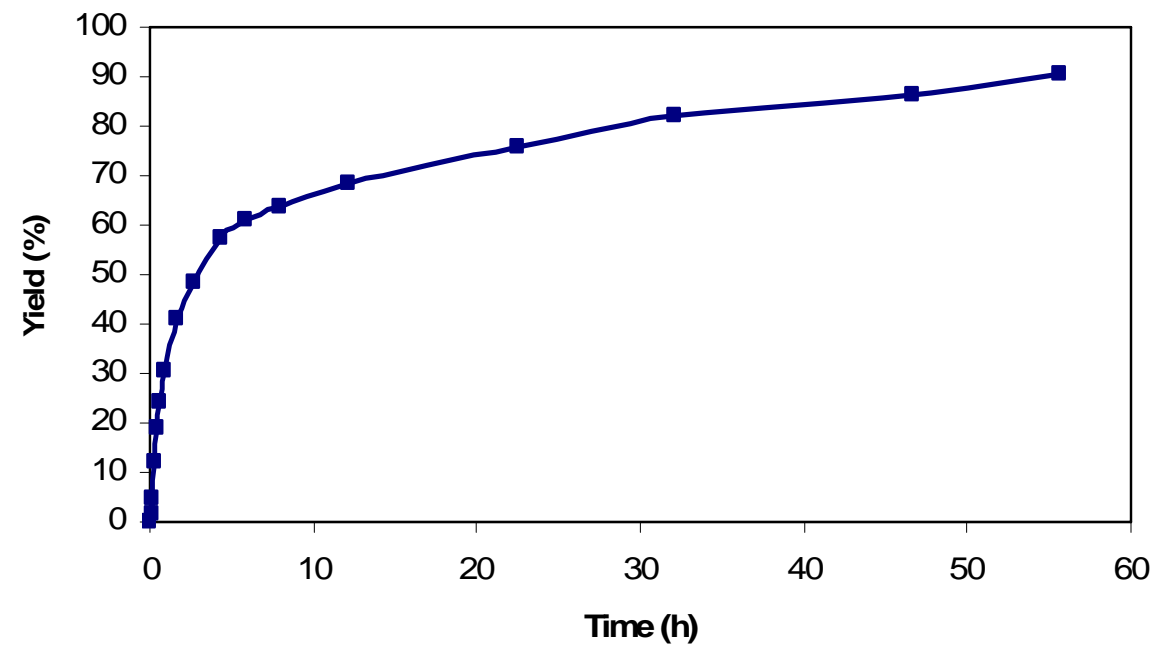

Figure S13. Pt (2.9 nm)/PVP/SBA-15 (1 mol\%). Recycle of catalyst with reduction/retreatment. 


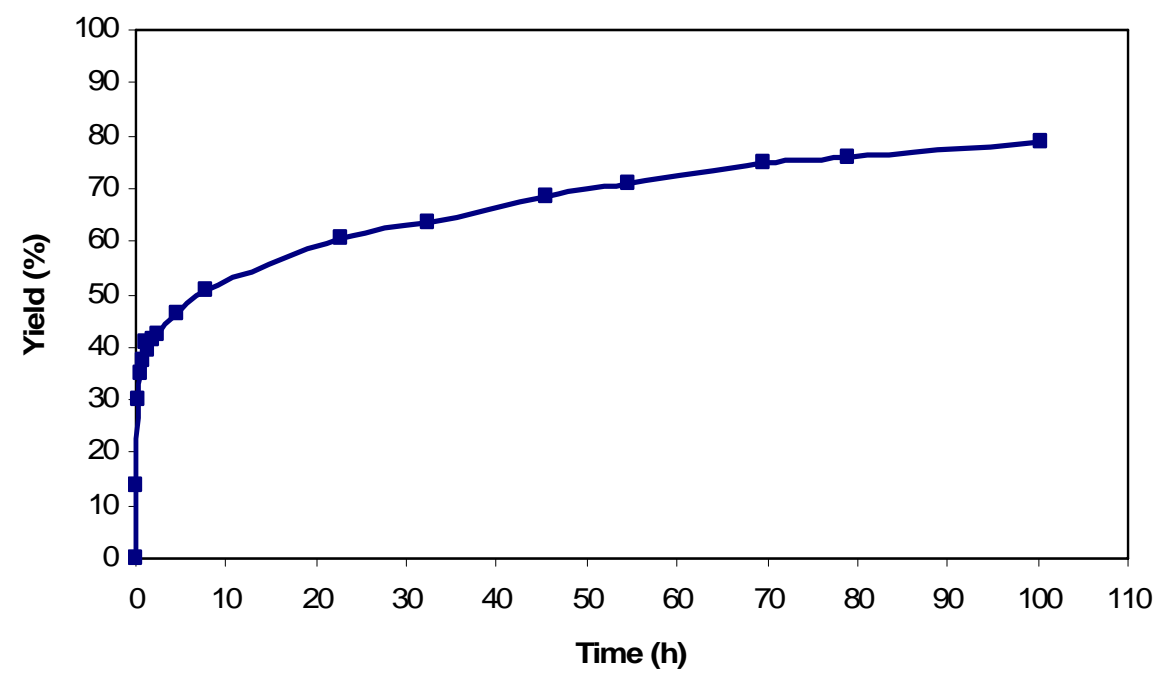

Figure S14. Pt (5.0 nm)/PVP/SBA-15 (2 mol\%). Initial use of catalyst.

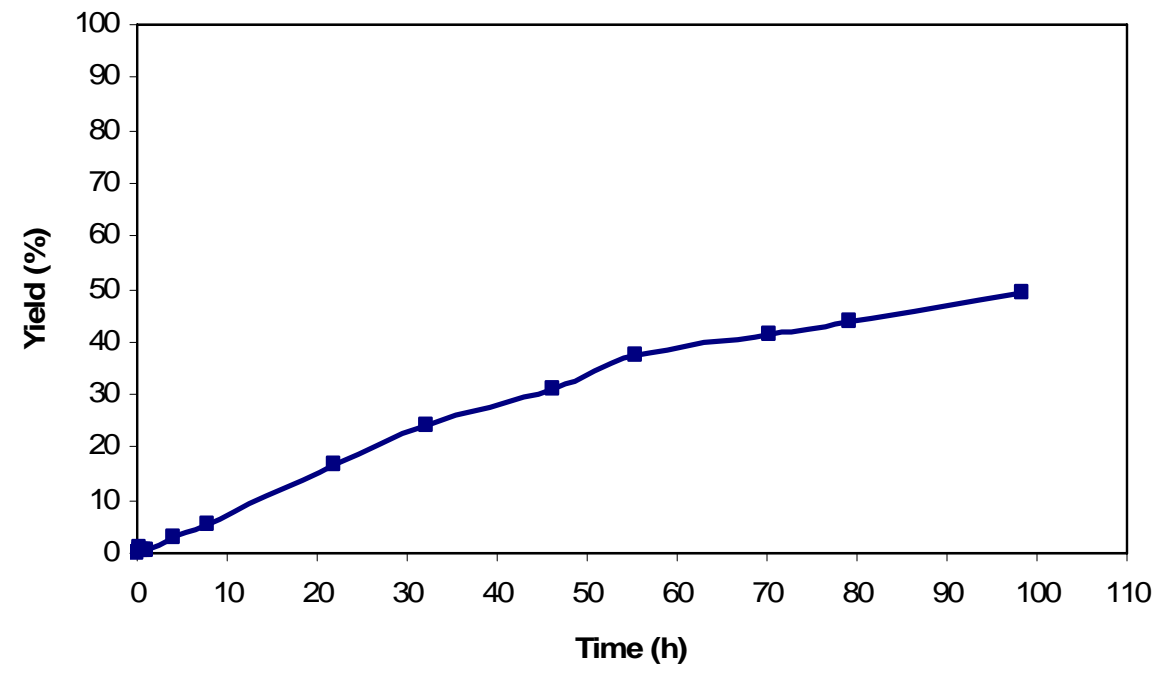

Figure S15. Pt (5.0 nm)/PVP/SBA-15 (2 mol\%). Recycle of catalyst without reduction/retreatment. 


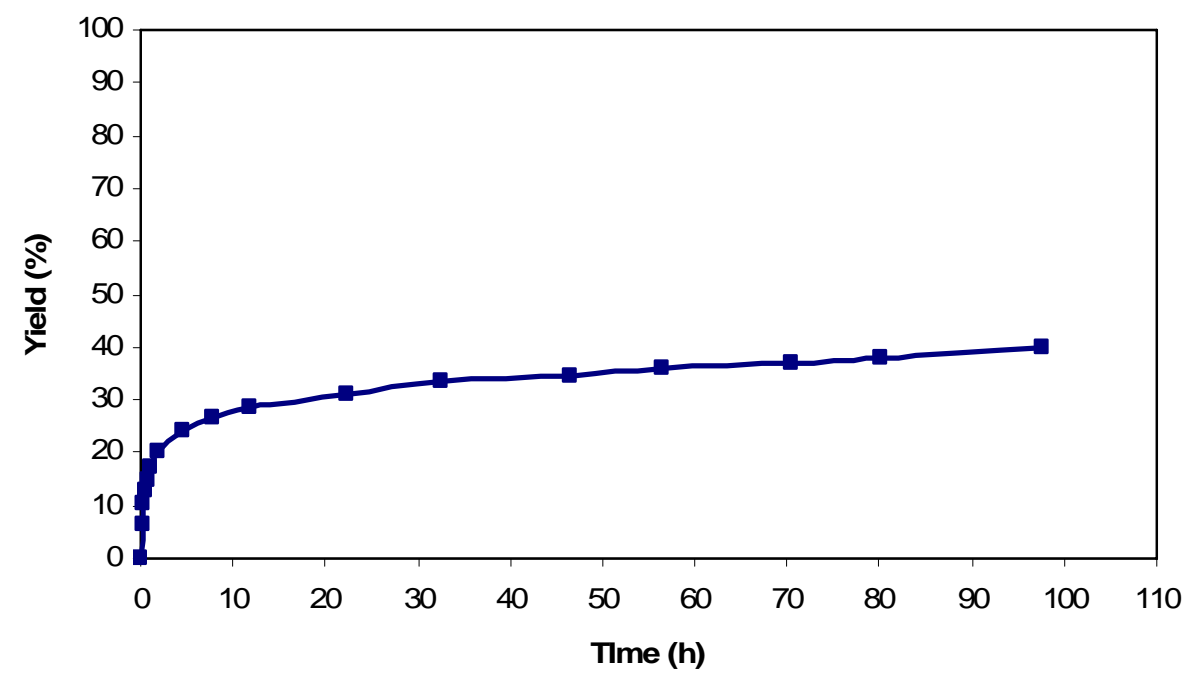

Figure S16. Pt $(5.0 \mathrm{~nm}) / \mathrm{PVP} / \mathrm{SBA}-15$ (2 mol\%). Recycle of catalyst with reduction/retreatment.

\section{ICP-MS Data}

Method: GLI Procedure ME-70

Analysis: Platinum

Before reaction $\mathrm{Pt}_{40} / \mathrm{G} 4 \mathrm{OH} / \mathrm{SBA}-15: 0.610 \%$ (basis: dried)

After reaction $\mathrm{Pt}_{40} / \mathrm{G} 4 \mathrm{OH} / \mathrm{SBA}-15: 0.662 \%$ (basis: dried)

Centrifuged solution with $\mathrm{Pt}_{40} / \mathrm{G} 4 \mathrm{OH} / \mathrm{SBA}-15$ removed (after treatment with $\mathrm{PhICl}_{2}$ ): 1.7 ppm (basis: as received) (det. limit: 1 ppm)

Filtered solution (glass microfiber filter) with $\mathrm{Pt}_{40} / \mathrm{G} 4 \mathrm{OH} / \mathrm{SBA}-15$ removed (after treatment with $\mathrm{PhICl}_{2}$ ): $<1.0$ ppm (basis: as received) (det. limit: 1 ppm)

\section{References}

1) Zielinska, A.; Skulski, L. Tetrahedron Lett. 2004, 45, 1087.

2) Scott, R. W. J.; Wilson, O. M.; Crooks, R. M. J. Phys. Chem. B 2005, 109, 692.

3) Huang, W.; Kuhn, J. N.; Tsung, C.-K.; Zhang, Y.; Habas, S. E.; Yang, P.; Somorjai, G. A. Nano Lett. 2008, 8, 2027.

4) Wang, Y.; Ren, J.; Deng, K.; Gui, L.; Tang, Y. Chem. Mater. 2000, 12, 1622.

5) Teranishi, T.; Hosoe, M.; Tanaka, T.; Miyake, M. J. Phys. Chem. B 1999, 103, 3818. 
6) Rioux, R. M.; Song, H.; Hoefelmeyer, J. D.; Yang, P.; Somorjai, G. A. J. Phys. Chem. B 2005, 109, 2192.

7) Song, H.; Rioux, R. M.; Hoefelmeyer, J. D.; Komor, R.; Neisz, K.; Grass, M.; Yang, P.; Somorjai, G. A. J. Am. Chem. Soc. 2006, 128, 3027.

8) Zhao, D.; Huo, Q.; Feng, J.; Chmelka, B. F.; Stucky, G. D. J. Am. Chem. Soc. 1998, 120, 6024.

9) Han, Y.; Lee, S. S.; Ying, J. Y. Chemistry of Materials 2007, 19, 2292.

10) Schmidt-Winkel, P.; Lukens, W. W.; Yang, P. D.; Margolese, D. I.; Lettow, J. S.; Ying, J. Y.; Stucky, G. D. Chemistry of Materials 2000, 12, 686.

11) Yang, H.; Shi, Q.; Tian, B.; Xie, S.; Zhang, F.; Yan, Y.; Tu, B.; Zhao, D. Chem. Mater. 2003, 15, 536.

12) Kuhn, J. N.; Huang, W. Y.; Tsung, C. K.; Zhang, Y. W.; Somorjai, G. A. J. Am. Chem. Soc. 2008, $130,14026$.

13) Ozturk, O.; Black, T. J.; Perrine, K.; Pizzolato, K.; Williams, C. T.; Parsons, F. W.; Ratliff, J. S.; Gao, J.; Murphy, C. J.; Xie, H.; Ploehn, H. J.; Chen, D. A. Langmuir 2005, 21, 3998.

14) Deutsch, D. S.; Siani, A.; Fanson, P. T.; Hirata, H.; Matsumoto, S.; Williams, C. T.; Amiridis, M. D. J. Phys. Chem. C 2007, 111, 4246.

15) Lang, H.; May, R. A.; Iversen, B. L.; Chandler, B. D. J. Am. Chem. Soc. 2003, 125, 14832.

16) Niu, Y. H.; Yeung, L. K.; Crooks, R. M. J. Am. Chem. Soc. 2001, 123, 6840.

17) Scott, R. W. J.; Ye, H. C.; Henriquez, R. R.; Crooks, R. M. Chem. Mater. 2003, 15, 3873.

18) Fürstner, A.; Davies, P. W. J. Am. Chem. Soc. 2005, 127, 15024.

19) Armarego, W.; Chai, L. F.; Christina, L. L. In Purification of Laboratory Chemicals, 5th Ed. Elsevier, 2003.

20) Yao, T.; Larock, R. C. J. Org. Chem. 2003, 68, 5936.

21) Uchiyama, M.; Ozawa, H.; Takuma, K.; Matsumoto, Y.; Yonehara, M.; Hiroya, K.; Sakamoto, T. Org. Lett. 2006, 8, 5517.

22) Zhang, Z.; Liu, C.; Kinder, R. E.; Han, X.; Qian, H.; Widenhoefer, R. A. J. Am. Chem. Soc. 2006, 128, 9066.

23) LaLonde, R. L.; Sherry, B. D.; Kang, E. J., Toste, F. D. J. Am. Chem. Soc. 2007, 129, 2452.

24) Fürstner, A.; Mamane, V. J. Org. Chem. 2002, 67, 6264.

25) Nakamura, I.; Sato, Y.; Terada, M. J. Am. Chem. Soc. 2009, 131, 4198.

26) Zhang, Q.; Shi, C.; Zhang, H.-R.; Wang, K. K. J. Org. Chem. 2000, 65, 7977. 


\section{DISCLAIMER}

This document was prepared as an account of work sponsored by the United States Government. While this document is believed to contain correct information, neither the United States Government nor any agency thereof, nor the Regents of the University of California, nor any of their employees, makes any warranty, express or implied, or assumes any legal responsibility for the accuracy, completeness, or usefulness of any information, apparatus, product, or process disclosed, or represents that its use would not infringe privately owned rights. Reference herein to any specific commercial product, process, or service by its trade name, trademark, manufacturer, or otherwise, does not necessarily constitute or imply its endorsement, recommendation, or favoring by the United States Government or any agency thereof, or the Regents of the University of California. The views and opinions of authors expressed herein do not necessarily state or reflect those of the United States Government or any agency thereof or the Regents of the University of California. 